\title{
EAl Endorsed Transactions

\section{Evaluation of Static Synchronous Compensator and Rail Power Conditioner in Electrified Railway Systems Using V/V and Scott Power Transformers}

\author{
Luis A. M. Barros ${ }^{1, *}$, Mohamed Tanta ${ }^{1}$, Antonio P. Martins ${ }^{2}$, Joao L. Afonso ${ }^{1}$ and J. G. Pinto ${ }^{1}$ \\ ${ }^{1}$ Centro ALGORITMI, University of Minho, Campus de Azurém, Guimarães, Portugal \\ ${ }^{2}$ SYSTEC Research Center, University of Porto, Porto, Portugal
}

\section{Abstract}

In this paper a comprehensive review of electrified railway systems is carried out, identifying the electric power quality deterioration which may appear due to nonlinear dynamic traction loads. Following this topic, a computational simulation of Static Synchronous Compensator (STATCOM) and Rail Power Conditioner (RPC) are presented, making a comprehensive analysis of each of these solutions regarding the power quality improvement in electrified railway systems. Four case studies are presented: (i) STATCOM evaluation when a traction power system is fed by a V/V power transformer; (ii) STATCOM evaluation when a traction power system is fed by a Scott power transformer; (iii) RPC evaluation when a traction power system is fed by a V/V power transformer; (iv) RPC evaluation when a traction power system is fed by a Scott power transformer.

Keywords: Electrified Railway System; Power Quality, Rail Power Conditioner; Scott Power Transformer; STATCOM; V/V Power Transformer.

Received on 05 September 2020, accepted on 08 February 2021, published on 29 March 2021

Copyright (C) 2021 Luis A. M. Barros et al., licensed to EAI. This is an open access article distributed under the terms of the Creative Commons Attribution license, which permits unlimited use, distribution and reproduction in any medium so long as the original work is properly cited.

doi: 10.4108/eai.29-3-2021.169164

\section{Nomenclature}

Instantaneous values of the compensation

$i_{\text {Comp_A }}$ currents synthesized by STATCOM in

$i_{\text {Comp_B }}, \quad$ phase $A$, phase $B$, and phase $C$,

$i_{\text {Comp_C }} \quad$ respectively.

Instantaneous values of phase $A$, phase $B$,

$i_{\text {Rail } A}$, $\quad$ and phase $C$ currents of the power

$i_{\text {Rail_B }}, \quad$ transformer primary windings (Scott or

$\left.i_{\text {Rail_C }} \quad \mathrm{V} / \mathrm{V}\right)$.
Instantaneous value of the compensation

$i_{\text {Comp_ }} x, \quad$ current synthesized by RPC in catenary $x$

$i_{\text {Comp_y }}, \quad$ and catenary $y$

$i_{x}, \quad$ Instantaneous values of catenary $x$ and

$i_{y} \quad$ catenary $y$ currents.

$i_{S_{-} A}, \quad$ Instantaneous values of phase $A$, phase $B$,

$i_{S_{-} B}, \quad$ and phase $C$ power grid currents.

$i_{S \_} C$

$i_{\text {Scott_x }}, \quad$ Instantaneous values of the catenary $x$ and $I_{\text {Scott } y} \quad$ catenary $y$ currents before the connection point of the RPC.

"Corresponding author. Email: 1barros@dei.uminho.pt 


$$
\begin{aligned}
& \text { is } x, \quad \text { Instantaneous values of the catenary } x \text { and } \\
& i s_{v y, y} \quad \text { catenary } y \text { currents before the connection } \\
& i s_{v v \_} \quad \text { point of the RPC. } \\
& v_{S_{-} A}, \quad \text { Instantaneous values of phase } A \text {, phase } B \\
& v_{S_{-} B}, \quad \text { and phase } C \text { power grid voltages. } \\
& v_{S_{-} C} \\
& v_{x}, \quad \text { Instantaneous values of catenary } x \text { and } \\
& v_{y} \quad \text { windings of the power transformer (Scott } \\
& \text { or } \mathrm{V} / \mathrm{V} \text { ). }
\end{aligned}
$$

\section{Introduction}

Rail transport is seen as the safest and more economical land transportation mode. In addition, it is recognized as one of the main catalysts for the economic growth of nations [1]-[3]. For instance, in the European case, railway transportation made more than 26.9 billion (26 900000000 ) individual trips in 2012, providing employment to 2.3 million people, reflecting a gross value of 143 billion Euros, more than air and sea transports [3]. Despite the strong impact of the rail transport mode on the industrial revolution in the early $18^{\text {th }}$ century, electrification of the railway lines had only occurred almost seventy years later.

In order to cover the railway transport demand, several incentive programs for the technological development of electrified railway system was created and expanded, such as the AVE (Alta Velocidad Espanhola) train in Spain, FRECC (Frecciarossa Trains) in Italy, ICE (InterCity Express) in Germany and TGV (Train à Grande Vitesse) in France. These programs allowed a rail growth of $17 \%$ from 2001 to 2012 in Europe. However, the continuous proliferation of electric locomotives caused a significant power quality deterioration in the three-phase electrical power grid.

Nowadays, power quality improvement in the threephase power grid is one of the major concerns for researchers. The problems of power quality affect not only the costs but also the functionality of some electronic equipment that are sensitive to power perturbation (e.g., medical and database equipment). In 2006 the Leonard Power Quality Initiative presented a study of power quality impact on the European industry, claiming that this type of problem caused losses of over $€ 150$ billion [4]. Figure 1 exemplifies the effect of the voltage waveform distortion as consequence of the current harmonics and unbalances, highlighting the electrified railway system.

Historically, the electrified railway represents a complex system capable of consuming an enormous amount of energy. On the other hand, power quality (PQ) phenomena could have a more severe impact when several electric locomotives are fed by the same catenary overhead line. Thus, from the electrical point of view, it is necessary to first understand the equivalent electric model of the locomotive as presented in [5] and in Figure 2.

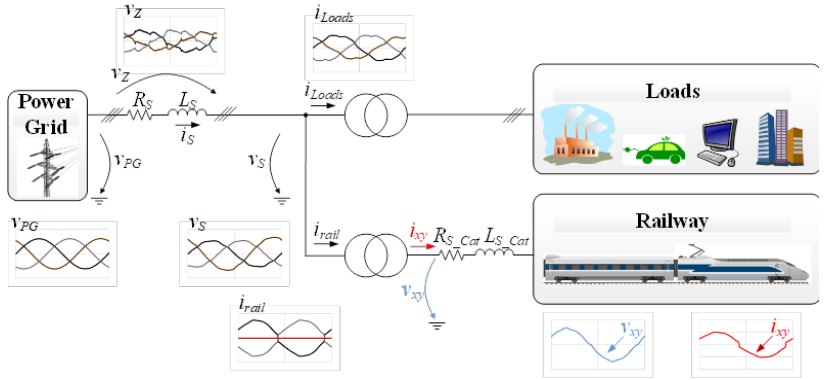

Figure 1. Exemplification of deterioration of the power grid voltages.

Some of the electrical model parameters are presented in Figure 2 and Table 1. Nevertheless, Table 1 also contains relevant information regarding the line impedances of the power grid as well as the impedances of the catenary of the railway system.

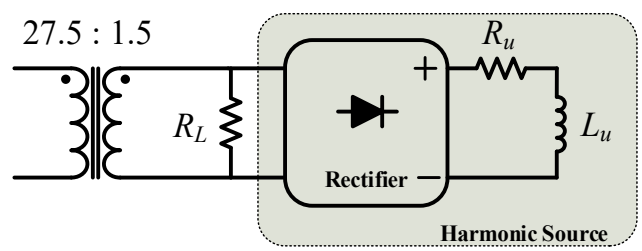

Figure 2. Electric model of an electric locomotive (based on [5]).

Despite being a representative model of an electric locomotive, it is important to highlight two major limitations of the electric model presented in Figure 2: i) the most evident is that it uses only passive components, thus preventing the simulation of regenerative braking, ii) considering that it is a model for high-speed locomotives in steady-state, a unitary power factor is considered, which prevents the variation of reactive power over time, as well as making it impossible to represent the locomotive's speed variation over the time. For this, a PQ-load model where the active power $(\mathrm{P})$ and reactive power $(\mathrm{Q})$ could be adjusted over time and would be more representative of an electric locomotive. However, despite being quite minimalist, the passive model was used to analyse power quality problems in a steady-state.

Considering the aforementioned information, it is expected that when an electric locomotive is connected to the catenary, different power quality phenomena arise, namely: three-phase current unbalance, harmonics, low power factor, and other transient phenomena. Some of these phenomena are represented in Figure 3.

Voltage unbalance represented in Figure 3 (a), is the most problematic issue caused by the electrified railway system. Considering that the electric locomotives are single-phase loads, they cause current and voltage unbalance in the three-phase power grid, producing currents with Negative Sequence Components (NSC) [7][9]. In this context, and considering the electric model 
presented in [5], a higher number of locomotives fed by the same catenary line signifies a higher power consumption, and consequently, a greater voltage drop in the power transmission line impedances represented in Figure 1. Despite the robustness of the railway system and allowing voltage variations of up to $16 \%$ above the nominal value and up to $76 \%$ of the nominal voltage as a minimum value, as shown in Table 2, the unbalances caused by the railway system need to be mitigated in order to overcome the above-mentioned problems.

Table 1. Model parameters (see Figure 1 for reference) of an electric locomotive, besides the line and the catenary impedances (based on [5], [6])

\begin{tabular}{lcl}
\hline & Values & Units \\
\hline$P_{\text {Train }}$ & 4800 & $\mathrm{~kW}$ \\
$R_{L}$ & 0.8 & $\Omega$ \\
$R_{u}$ & 1 & $\Omega$ \\
$L_{u}$ & 2 & $\mathrm{mH}$ \\
$R_{S}$ & 0.2 & $\Omega / \mathrm{km}$ \\
$X_{s}$ & 0.7 & $\Omega / \mathrm{km}$ \\
$R_{S_{-} \text {cat }}$ & 0.15 & $\Omega / \mathrm{km}$ \\
$X_{\text {Cat }}$ & 0.45 & $\Omega / \mathrm{km}$ \\
\hline
\end{tabular}

Table 2. Voltage range values allowed in the $25 \mathrm{kV}$ AC electrified railway system [2].

\begin{tabular}{lcl}
\hline & Values & Units \\
\hline Highest non-permanent voltage & 29 & $\mathrm{kV}$ \\
Highest permanent voltage & 27.5 & $\mathrm{kV}$ \\
Nominal Voltage & 25 & $\mathrm{kV}$ \\
Lowest permanent voltage & 19 & $\mathrm{kV}$ \\
Lowest non-permanent voltage & 17.5 & $\mathrm{kV}$ \\
\hline
\end{tabular}

Harmonic contents represented in Figure 3 (b), is the second most severe phenomenon of electrical railway systems. The electric locomotives use AC-DC-AC power converters to adjust the electric quantities (voltage, current, and/or frequency). The first stage of conversion being commonly constituted by a diode bridge rectifier [7]. In turn, there are already solutions that use semi-controlled semiconductors and fully-controlled semiconductors, using for this purpose thyristors, Gate-Turn-Off (GTO), and Insulated-Gate Bipolar Transistor (IGBT) [10]. Some phenomena associated with this system are identified in [7], [8]. In [11] are presented examples of harmonic components in a three-phase $220 \mathrm{kV}$ electrical power grid, as well as presented a performance evaluation of a Static Synchronous Compensator (STATCOM) in these operation conditions.

A unitary value of the power factor indicates low reactive power. In turn, the presence of high reactive power reflects a low power transmission system efficiency [8]. Despite the need for reactive power to the traction system, in the case of an inductive load, its value must be reduced to avoid higher transmission energy losses. This ambiguity can be mitigated by the addition of active power conditioners capable of locally produce the required reactive power, thus reducing the losses in the power grid and, consequently, the energy costs [7]. An example of a system with a non-unitary power factor is represented in Figure 3 (c).

The catenary height, the pantograph wear and the transition between Neutral Sections (NS) are some of the intermittent operations of the electric locomotive. These momentary operations may originate transients phenomena being able to damage the rail equipment [7], [12], as shown in Figure 3 (d).

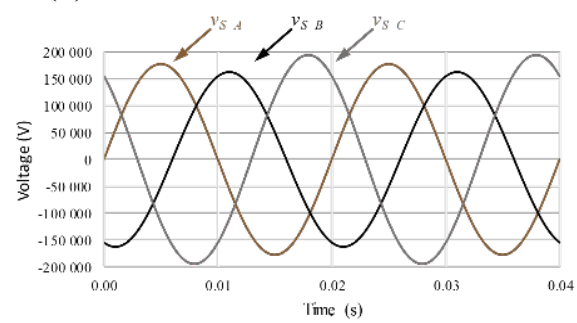

(a)

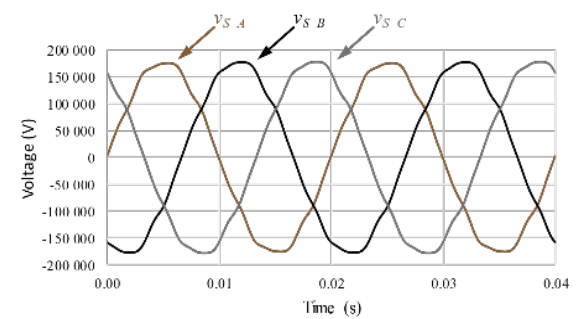

(b)

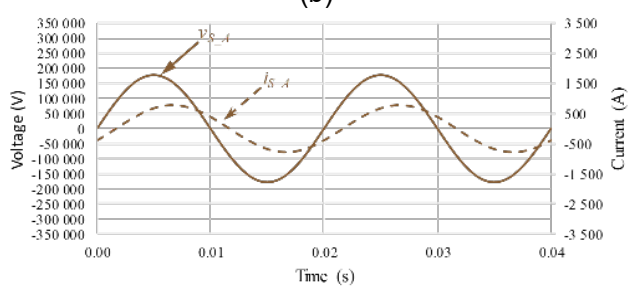

(c)

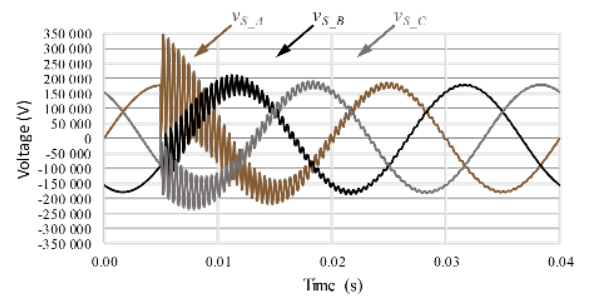

(d)

Figure 3. Examples of power quality phenomena: (a) Voltage unbalance; (b) Voltage harmonics; (c) Low power factor; (d) Voltage transients.

Considering the above-mentioned topics, this paper presents a study of the STATCOM and the RPC compensating power quality phenomena in electrified railway systems, powered by $\mathrm{V} / \mathrm{V}$ and Scott power transformers. In this sense, this work is organized as follows: in section 1, an introduction to the research topic is carried out, presenting examples of PQ phenomena in the traction power grid; section 2 presents different studies in the literature related to the same topic of this paper: 
section 3 presents the current solutions to overcome the power quality deterioration, considering the STATCOM and the RPC systems; section 4 mainly presents the simulation results of the STATCOM and the RPC with V/V and Scott power transformers. Moreover, a comparative analysis of the two systems is presented; section 5 summarizes the main conclusion of this work.

\section{Related Work}

Interesting studies can be found in the literature, related to the introduction of power electronics converters to mitigate power quality phenomena in electrified railway feeding systems, however there are some research gaps in terms of comparing different solutions, as well as different states of operation.

The analysis of STATCOM robustness against voltage sags and voltage swells is presented in [13]. The authors considered a STATCOM total power of $10 \mathrm{MVA}$ connected to a $63 \mathrm{kV}$ high-voltage distribution power grid. In addition, $\mathrm{V} / \mathrm{V}$ power transformers were used to interface with two $27.5 \mathrm{kV}$ overhead catenary lines. The simulations were carried out considering two scenarios: (1) when the load behaved as a constant current source; (2) when the load behaved as a constant power source. Qualitative and quantitative data are presented. In that study, the analysis was limited to just one case study: STATCOM with a V/V power transformer, and a single locomotive on one side of the traction power grid. A similar study was presented in [14], where only qualitative analysis was presented for three STATCOM models and the associated control algorithms. The study in [14] was carried out with the same simulations parameters and considerations as in [13].

In [15], the authors presented a study of an RPC to compensate power quality problems in high-speed railway systems powered by Scott power transformers. In that study, it was considered a load with an apparent power of 15 MVA connected to the catenary. Due to that configuration, there was a significant unbalance traction power supply system, with a phase $y$ supply current with an amplitude of $777 \mathrm{~A}$ and phase $x$ supply current with zero aplitude. Once the RPC was turned on, it was possible to reduce the three-phase unbalance from $50 \%$ to $2.5 \%$. In that study the analysis is limited to just one case study: RPC, Scott power transformer, and a single locomotive on one side of the traction system.

In [16], RPC performance was analysed when the traction system was powered with the V/V transformer or the Scott transformer. A $15 \mathrm{MVA}$ load power and $27.5 \mathrm{kV}$ overhead catenary line voltage were considered. Once again, the analysis was performed only with a locomotive on one side of the railway traction system, more specifically, on the catenary $y$ side. In that study, the analysis was limited to two case studies: RPC, V/V and Scott power transformer, and a single locomotive on one side of the traction system. Another study of an RPC based on MMC, was presented in [17], where both sides of the overhead catenary lines were considered to have a traction load, despite different values of power on each side. That is, on the catenary $x$ side, it was considered an electric locomotive with 4.8 MW, and on the catenary $y$ side, it was considered an electric locomotive with $2.4 \mathrm{MW}$. The simulation results proved qualitatively the correct functioning of the system. In that study the analysis was limited to just one case study: RPC, V/V power transformer, and two different locomotives, one on each side of the traction system. Another study was presented in [18], where authors analysed different topologies from MMC to RPC for a rail supply system powered by the $\mathrm{V} / \mathrm{V}$ or Scott power transformers. Once again, unequally loaded sections were considered (4.8 MW on the catenary $x$ side and $2.4 \mathrm{MW}$ on the catenary $y$ side). Consequently, a comparative study of a STATCOM with an RPC would be noteworthy, considering similar simulation models for a better comprehensive analysis. Moreover, it would be interesting to analyse the load unbalance in the overhead catenary lines, considering the same load on both catenary sides and how this may affect the three-phase current unbalance. Power unbalance analyses on the three-phase system would also be interesting for a correct sizing of the active power conditioners. The difference of using V/V or Scott power transformers would also be interesting to analyse.

Other technical questions addressed in this study of the impact of the asymmetrical loads on the catenary side (power on the catenary $x$ side is greater than the power on the catenary $y$ side; or, the power on the catenary $y$ side is greater than the power on the catenary $x$ side) affect the operation of the three-phase power grid.

\section{Railway Power System}

In the combustion-engine locomotives, clean and noiseless solutions are required when passing through residential areas and with fewer vibrations for better passenger comfort. The electrified railway system presents a viable solution that meets these requirements. In addition, there is a range of potentialities that can be explored, such as the integration of renewable energies and the energy recovering from regenerative braking. In [19], a study of the trends of the railway electrical system is carried out, highlighting the integration of concepts such as renewable energy, on-board and off-board energy storage of different technologies, hourly combination with cooperative strategies as well as regenerative braking. The paper also presents some trends in terms of power electronics solutions for railway applications. However, this system is still complex and needs to be investigated. This chapter discusses the existing solutions to overcome the PQ deterioration.

\subsection{Conventional Railway Power System}

Considering that electric locomotives are single-phase loads, the installation of a single-phase power transformer in a substation would locally intensify the unbalance of the 
system [20]. For that reason, other power supply schemes are used to reduce this problem. One of the most basic, inexpensive and old method is to alternate phase connections of the power transformers with the three-phase power grid, being commonly referred in the literature as a phase-shift method. This method allows reducing the NSC and, consequently, the system unbalance [8]. For better performance, two power transformers, in different phases, are usually used in a given substation, and the connections in the adjacent substations are shifted.

The catenary may be supplied by the electrical power grid with different amplitudes and phases. Therefore, it is necessary to create NS, in order to avoid short circuits between different phases of the power grid. The NS can extend from several meters up to some kilometers [7], [12], [20]. This requirement prevents the power flow of the adjacent substations, as well as causing a feed interruption when passing through the NS, causing power perturbations [7], [21]. Despite being a simple solution, it presents high robustness due to the overloading capability and the long-life cycle of the power transformers. Despite the reduction of current unbalance, the unbalance still remains.

Considering the rapid growth of railway networks, it is necessary to implement solutions capable of meeting the new power quality requirements. Thus, other configurations using three-phase power transformers are employed, namely the $\mathrm{V} / \mathrm{V}$, Scott, Le Blanc, Impedance Matching, and Woodbridge power transformers [22].

$\mathrm{V} / \mathrm{V}$ power transformer is the most used in railway applications due to its simple construction and high overloading capability. The transformation ratio is given by $N 1: N 2$, which represents the relation between the threephase power grid voltages and the catenary voltage. [22], [23]. These power transformers are sized to provide the power required by the single-phase traction loads (e.g., $\mathrm{V} / \mathrm{V}$ transformer nominal power is comprised between 40 MVA and 60 MVA [1], [8]). On the other hand, Scott power transformer is one of the emerging solutions for rail systems powering. Its versatility in balancing operating conditions on the three-phase power grid side contrasts with the complexity at the construction level. However, the performance of the special arrangement power transformer is limited and the integration of active power conditioners is important in order to dynamically compensate the power quality phenomena. From this perspective, active power conditioners in conjunction with three-phase transformers presents an interesting solution to overcome the power quality phenomena.

\subsection{Power Conditioners for Railway Power Systems}

With the evolution of technology in power electronics and the introduction of semiconductors, it was possible to present and implement more flexible solutions in the compensation of power quality phenomena. In this context, active power conditioners present themselves as a very attractive solution to the requirements of the existing electrical system. Some examples of active power conditioners are the Static VAr Compensator (SVC), STATCOM, Static Frequency Converter (SFC), and RPC. The functionality of the above-mentioned systems is presented with more detail in [7], [8], [12], and [16]. STATCOM control algorithm is presented in [24] for the compensation of power quality phenomena. On the other hand, selective control algorithms to be implemented in $\mathrm{RPC}$ are presented in [5].

The main contribution of this paper lies essentially in the analysis and comparison of two solutions of active power conditioners, the STATCOM and the RPC, under similar operating conditions. In the next topic, each of the topologies is analysed in detail, with simulation results being presented.

\section{Simulation Results}

In this item are analysed two active power conditioners: the STATCOM shown in Figure 6 and the RPC shown in Figure 9. Nevertheless, topologies of three-phase to two-phase power transformers (V/V and Scott) was considered in this study, being highlighted in each figure. Still in this topic, the methodology as well as the control algorithms implemented in each situation are presented, with a more detailed analysis being presented in each sub-topic. In the simulation, it was considered that the power substation is $50 \mathrm{~km}$ away from the point of power supply of the railway system, where the V/V or the Scott power transformer was coupled. The electric locomotive, in turn, was $10 \mathrm{~km}$ away from the power transformer. Therefore, the parameters $R s, L s, R_{s_{-} c a t}$ and $L_{s_{-} \text {cat }}$ have been adjusted accordingly. The parameters considered in the simulation are presented in Table 3.

Table 3. Parameters considered in the simulation.

\begin{tabular}{ccc}
\hline & Values & Units \\
\hline$R s$ & 10 & $\Omega$ \\
$L s$ & 111 & $\mathrm{mH}$ \\
$R_{S_{-} c a t}$ & 1.5 & $\Omega$ \\
$L_{s_{-} c a t}$ & 14 & $\mathrm{mH}$ \\
Sampling frequency & 50 & $\mathrm{kHz}$ \\
Switching frequency & 20 & $\mathrm{kHz}$
\end{tabular}

The THD analysis was performed only at the moment when a locomotive was found on each catenary side, using 3 cycles of the power grid fundamental frequency to determine the THD value.

Regarding the determination of the current unbalance ratio, the relationship between the NSC and the Positive Sequence Components (PSC) was considered. To determine these parameters, the average value of the NSC and PSC was measured during three cycles of the power grid voltage, when the STATCOM or the RPC was already in steady state operation. 


\subsection{Simulation Results of the Railway System with V/V and Scott Power Transformers}

In order to analyse the performance of STATCOM or RPC to compensate the PQ problems in the electrified railway system, a preliminary study of the railway system powered by the $\mathrm{V} / \mathrm{V}$ or Scott power transformers was carried out. In this way, it was possible to have a comparison between RPC and STATCOM when the active power conditioners are connected. In order to analyse the spread of power quality problems in the railway system, sinusoidal voltages on the side of the electrical power grid distribution were considered, analysing the voltages and currents in different operating conditions of the railway system.

For the following explanation, it is necessary to refer that different load scenarios were considered, as presented in Figure 4 (a) and Figure 5 (a), for the V/V and Scott power transformers, respectively. At the time instant of $0.02 \mathrm{~s}$ an electric locomotive was added in the catenary $x$, and after the time instant of $0.04 \mathrm{~s}$ the locomotive was moved to the catenary $y$. At the time instant of $0.1 \mathrm{~s}$ another locomotive was added to the catenary $x$, thus heaving a locomotive in each catenary. At the time instant of $0.16 \mathrm{~s}$ there was two locomotives in the catenary $y$ and only one in the catenary $x$, reflecting an unbalance load scenario. Finally, a symmetrical unbalanced load scenario is represented at the time instant $0.2 \mathrm{~s}$, where there was two electric locomotives in the catenary $x$ and only one in the catenary $y$. These load ratings over time is reflected in currents $i_{x}$ and $i_{y}$, in the catenary $x$ and catenary $y$, respectively. This load scenario was replicated in all simulations, with each event highlighted in the results presented in different shaded colours. In this context:

- $\quad$ Figure 4 (b) and Figure 5 (b) represents the three-phase power grid voltages, $v_{S_{A}}, v_{S_{B} B}$, and $v_{S_{C}}$;

- Figure 4 (c) and Figure 5 (c) represents the three-phase power grid currents $i_{S_{-} A}, i_{S_{-} B}$, and $i_{S_{-} C}$;

- Figure 4(d) and Figure 5(d) represents the catenaries $x$ and $y$ voltages at the secondary windings of the power transformer, $v_{x}$, and $v_{y}$;

- $\quad$ Figure 4 (e) and Figure 5 (e) represent the currents in the catenaries $x$ and $y, i_{x}$ and $i_{y}$.

In order to evaluate the overall STATCOM and RPC performances with a V/V or a Scott power transformer, the total harmonic distortion (THD) ratio was calculated at the moment when catenary load sections $x$ and $y$ were equally loaded. It should be highlighted that these values, presented in Table 4, were obtained without any dynamic compensation by the STATCOM or by the RPC.

It is possible to verify the existence of harmonic contents in the voltages and in the currents, where the current waveforms contain a higher ratio of THD as presented in Figure 4 and Figure 5. In addition, almost similar THD ratios were obtained when using the $\mathrm{V} / \mathrm{V}$ or the Scott power transformer. In general, V/V and Scott power transformers do not totally overcome the PQ deterioration and they cannot follow the dynamic behavior of the nonlinear load. With this in mind, a dynamic compensator based on power electronics (e.g., STATCOM or RPC) is required.

Table 4. THD ratio in the voltages and currents at the three-phase power grid and the railway power system, using V/V or Scott power transformers.

\begin{tabular}{cccccc}
\hline & $v_{S \_}$ & $v_{S B}$ & $v_{S C}$ & $v_{x}$ & $v_{y}$ \\
\hline V/V & $0.693 \%$ & $0.763 \%$ & $0.744 \%$ & $0.703 \%$ & $0.764 \%$ \\
Scott & $0.634 \%$ & $0.748 \%$ & $0.659 \%$ & $0.631 \%$ & $0.717 \%$ \\
\hline & $i_{S \_} A$ & $i_{S \_B}$ & $i_{S \_} C$ & $i_{x}$ & $i_{y}$ \\
\hline V/V & $12.0 \%$ & $12 \%$ & $8.66 \%$ & $12.0 \%$ & $12 \%$ \\
Scott & 11.65 & $11.9 \%$ & $11.8 \%$ & $11.6 \%$ & $12.0 \%$ \\
\hline
\end{tabular}

Simulation Results of the Railway System Powered by V/V Power Transformer

In relation to the railway power system powered by $\mathrm{V} / \mathrm{V}$ power transformer, it is possible to verify that $v_{S A}, v_{S B}$, $v_{S_{-} C}, v_{x}$, and $v_{y}$, shown in Figure 4 (b) and Figure $4(\bar{d})$, present a sinusoidal waveform.

At the time instant of $\mathrm{t}=0 \mathrm{~s}$, the railway system was operating without load, and it is possible to see that $v_{\mathrm{x}}$ lags $v_{S_{A}}$ by $30^{\circ}$. On the other hand, $v_{y}$ is $60^{\circ}$ behind in relation to $v_{x}$, that is, it lags the $v_{S_{-} A}$ by $90^{\circ}$. When a locomotive is added in the catenary $x$, at the time instant of $\mathrm{t}=0.02 \mathrm{~s}$, it can be verified the existence of $i_{x}$ with high THD ratio. This phenomenon is reflected in the waveforms of $i_{S A}$ and $i_{S} C$. After the time instant $0.04 \mathrm{~s}$, the electric locomotive passes to the catenary $y$ side, replicating the simulation results obtained in the previous instant, being at this time the phase $B$ and $C$ of the three-phase power grid responsible for powering the railway system. Consequently, the current $i_{S_{-} B}$ and $i_{S_{-} C}$ present a high THD ratio. Additionally, in these two scenarios, it can be seen a three-phase high currents unbalance when only one side of the catenary is loaded.

At the time instant of $\mathrm{t}=0.10 \mathrm{~s}$, there was two locomotives in the railway power system, one in the catenary $x$ and the other in the catenary $y$, consuming a current $i_{x}$ and $i_{y}$, respectively. These two currents are in phase with the respective voltages of the catenary side $v_{x}$ and $v_{y}$. Once again, $i_{S_{-} A}, i_{S_{-} B}$, and $i_{S_{-} C}$ reflect the nonsinusoidal waveform of the catenary side currents, being the current $i_{S_{A} A}$ in phase with $i_{x}$ and $i_{S_{-} B}$ in phase with $i_{y}$. Besides, summing $i_{S_{-} A}$ with $i_{S_{-} B}$ results in $i_{S_{-} C}$.

At the time instant of $\mathrm{t}=0.16 \mathrm{~s}$, a railway system powered by $\mathrm{V} / \mathrm{V}$ power transformer, another unbalance scenario was considered in the simulation, in which, catenary $x$ has one locomotive and catenary $y$ has two locomotives. At this moment, it can be verified that the waveforms of $i_{x}$ and $i_{y}$, as well as the currents $i_{S A}, i_{S B}$ and $i_{S_{-} C}$, are distorted. Considering the locomotives are equal and the catenary $y$ has double the load value of catenary $x$, it can be seen that $i_{y}$ has twice the amplitude of $i_{x}$. Consequently, $i_{S_{-} B}$ will also have twice the amplitude of 
$i_{S A}$. Once again, by adding these two currents, results in $i_{S C}$, having a 2.6 times greater amplitude than $i_{S A}$.

Finally, at the time instant of $\mathrm{t}=0.2 \mathrm{~s}$, a similar case scenario to the previous situation was considered, with catenary $x$ this time having two locomotives and, in turn, catenary $y$ only one. Once again, it is possible to see that the currents $i_{x}$ and $i_{y}$, as well as $i_{S_{-} A}, i_{S_{-} B}$, and $i_{S_{-} C}$, are distorted. Considering that the locomotives are the same and that catenary $x$ has twice the load of catenary $y$, it is possible to verify that $i_{x}$ now has twice the value of $i_{y}$. Analyzing the currents on the side of the power grid, it is possible to verify that $i_{S_{-} B}$ and $i_{S_{-} C}$ have very similar amplitudes. In turn, $i_{S_{A} A}$ has twice the amplitude of $i_{S_{B} B}$ and $i_{S} C$. Once again, by adding these two currents, results in $i_{S_{-} C}$, having a 2.6 times greater amplitude than $i_{S_{-} B}$. With that, it can be concluded that the $\mathrm{V} / \mathrm{V}$ power transformer provides symmetric operation if the highest load is the catenary $x$ or in the catenary $y$.

\section{Simulation Results of the Railway System} Powered by Scott Power Transformer

Similarly, to the V/V power transformer, computational simulations were used to study the operation principle of

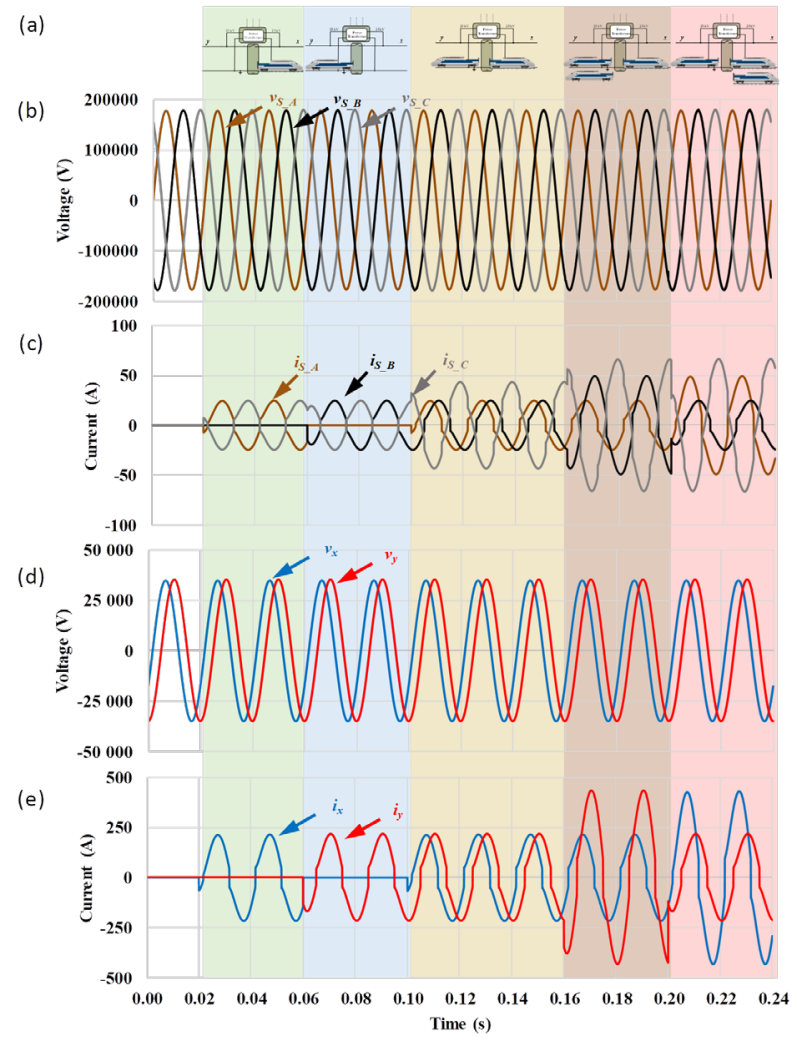

Figure 4. Simulation results of the railway system powered by a V/V power transformer: (a) Case scenarios with different number of locomotives in the catenaries; (b) Three-phase power grid voltages $V s_{-} A, V s_{-} B$ and $V s_{-} c$; (c) Three-phase power grid currents is_A, is_B, is_c; (d) Voltage in the catenaries, $v_{x}$ and $v_{y} ;(\mathrm{e})$ Currents in the catenaries, $i_{x}$ and $i_{y}$. the Scott power transformer with more detail, being the simulation results presented in Figure 5.

At the time instant of $\mathrm{t}=0 \mathrm{~s}$, the railway system is operating without load, being possible to see that $v_{x}$ is in phase with $v_{S_{A} A}$. On the other hand, $v_{y}$ is $90^{\circ}$ behind in relation to $v_{x}$, that is, it lags the $v_{S_{-} A}$ by $90^{\circ}$.

When a locomotive is added in the catenary $x$, at the time instant of $\mathrm{t}=0.02 \mathrm{~s}$, it can be verified the existence of $i_{x}$ with THD ratio. However, it should be noted that on the power grid side, and unlike the $\mathrm{V} / \mathrm{V}$ power transformer, all phases contribute to supply the railway system. Although all the phases contribute to the feeding of the system, $i_{S_{-} A}$ is double than $i_{S_{-} B}$ and $i_{S_{-} C}$.

After the time instant of $\mathrm{t}=0.04 \mathrm{~s}$, the electric locomotive passes to the catenary $y$ side, creating a different phenomenon from the one existed in the previous instant. When only locomotives are found in the catenary $y$, the unbalance ratio is higher, existing only $i_{S_{B} B}$ and $i_{S_{-} C}$ to contribute with the feeding of the railway system.

At the time instant of $\mathrm{t}=0.10 \mathrm{~s}$, there are two locomotives in the railway power system, one in the catenary $x$ and the other in the catenary $y$, consuming a current $i_{x}$ and $i_{y}$, respectively. These two currents are in phase with the respective voltages of the catenary side $v x$

(a)

(b)

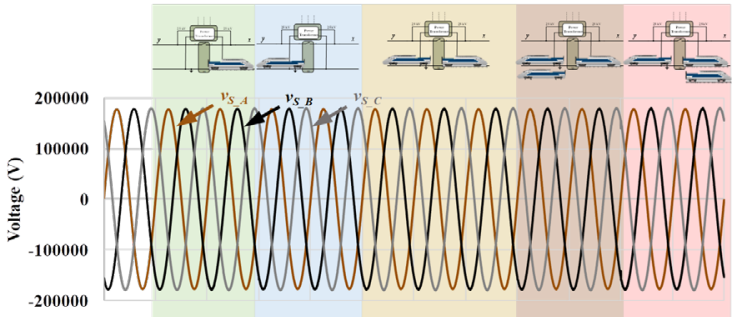

(c)

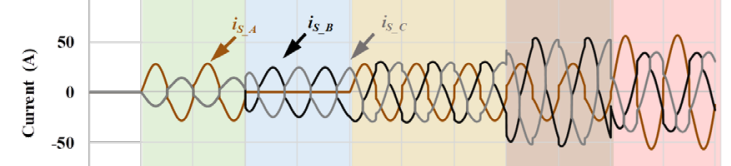

(d)
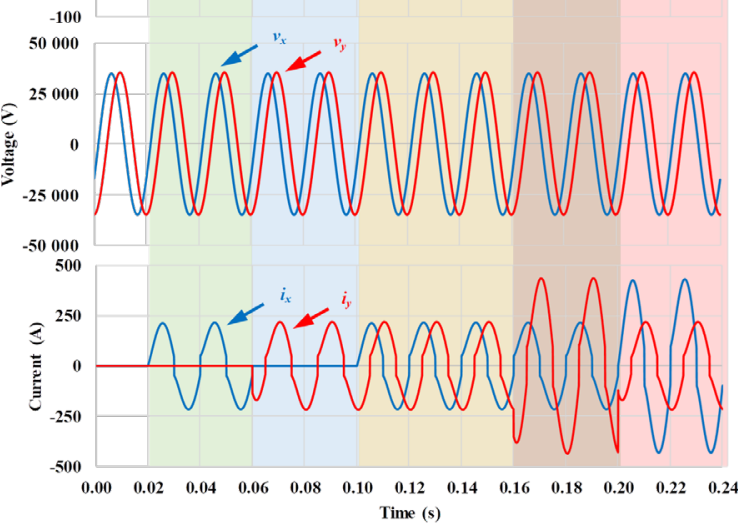

Figure 5. Simulation results of the railway system powered by a Scott power transformer: (a) Case scenarios with different number of locomotives in the catenaries; (b) Three-phase power grid voltages $V s_{-} A, V s_{-} B$ and $V s_{-} c$; (c) Three-phase power grid currents is $A$, is $B$, is $s_{-}$; (d) Voltage in the catenaries, $v_{x}$ and $v_{y} ;(\mathrm{e})$ Currents in the catenaries, $i_{x}$ and $i_{y}$. 
and $v_{y}$. Once again, $i_{S \_}, i_{S B}$, and $i_{S C}$ reflect the nonsinusoidal waveform of the catenary side currents, being $i_{x}$ in phase with $i_{S} A$ and $i_{y}$ lags $90^{\circ}$ the current $i_{x}$. However, it should be noted that, in this case, the currents on the power grid side have similar amplitudes, making the system more balanced.

At the time instant of $\mathrm{t}=0.16 \mathrm{~s}$, a railway system powered by Scott power transformer, another unbalance scenario was considered in the simulation, in which, catenary $x$ has one locomotive and catenary $y$ has two locomotives. At this moment, it can be verified that the waveforms of $i_{x}$ and $i_{y}$, as well as the currents $i_{S_{-} A}, i_{S_{-} B}$, and $i_{S} C$, are distorted. Considering that the locomotives are equal and the catenary $y$ has double the load value of catenary $x$, it can be seen that $i_{y}$ has twice the amplitude of $i_{x}$. On the other hand, $i_{S_{-} A}$ maintains its previous amplitude, and $i_{S B}$ and $i_{S C}$ increase 1.8 times.

Finally, at the time instant of $\mathrm{t}=0.2 \mathrm{~s}$, a similar case scenario to the previous case was considered, with catenary $x$, this time, having two locomotives and, in turn, catenary $y$ only one. Once again, it is possible to see that the currents $i_{x}$ and $i_{y}$, as well as $i_{S_{-} A}, i_{S_{-} B}$ and $i_{S_{-} C}$, are distorted. Considering that the locomotives are equal and that catenary $x$ has twice the load of catenary $y$, it is possible to verify that $i_{x}$ now has twice the value of $i_{y}$. Analysing the currents on the side of the power grid, it is possible to verify that $i_{S B}$ and $i_{S C}$ have very similar amplitudes. In turn, $i_{S A}$ has a 1.5 times greater amplitude than $i_{S_{-} B}$ and $i_{S_{-} C}$. Despite the difference in amplitudes, in this case scenario, the values of the currents are not so different from the previous case, and it can be concluded that the greater the load on the catenary $y$, the greater the current unbalance of the three-phase power grid that feeds the railway system.

Analyzing the obtained data it is possible to verify that the Scott power transformer allows a balance of the threephase currents of the power grid when the two sections of the catenary are equally loaded. In this scenario, the use of Scott power transformers allows a reduction in the nominal powers of the active conditioners to be incorporated in the three-phase system, namely in the value of the reactive compensation power. However, the Scott power transformer has a greater complexity in its development and, consequently, a higher cost.

Nevertheless, and analysing the operating modes of the two transformers, it was possible to verify that the $\mathrm{V} / \mathrm{V}$ transformer has a symmetrical mode of operation, which is not the case with the Scott transformer. That is, with the $\mathrm{V} / \mathrm{V}$ transformer the same relationship is always obtained between the amplitudes of the currents of the three-phase power grid, three waveforms with a high, medium, and low amplitude, when two electric locomotives are found in section $y$ and one in section $x$ or just an electric locomotive in section $\mathrm{y}$ and two in section $x$. In turn, with the Scott transformer, when two locomotives found in section $y$ and only one in section $x$, two current waveforms of high amplitude and a third waveform of reduced amplitude are obtained. When there is only one locomotive in section $y$ and two in section $x$, two medium amplitude waveforms and a third high amplitude waveform are obtained.
Scott transformer has some disadvantages in terms of costs and the material (iron and copper) utilization factor. A higher material utilization factor signifies a smaller transformer volume at the same nominal power. The material utilization factors of Scott is $81.6 \%$. However, the utilization factor of the unbalance $\mathrm{V} / \mathrm{V}$ power transformer could reach up to $94 \%$. Further to this, the required voltage insulation level is high for the Scott transformers since there is no neutral point in the primary windings of these transformers [22], [25].

\subsection{Simulation Results of the Railway System with a STATCOM and Power Transformers}

The STATCOM, shown in Figure 6, takes an advantage of the technological evolution of the semiconductors, switching at higher frequencies when compared to the SVC, presenting in this way an attractive solution to mitigate power quality phenomena, such as harmonics, NSC and reactive power [8].

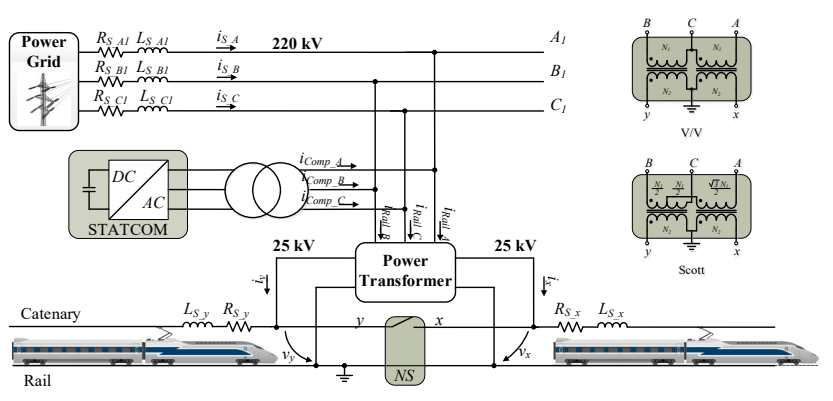

Figure 6. Electrical schematic of the STATCOM connection with the railway power system powered by $\mathrm{V} / \mathrm{V}$ or Scott transformers.

As can be seen, this solution is composed by a DC-bus followed by a voltage source DC-AC power converter. The STATCOM is connected, in shunt, between the three-phase power grid and the railway power system. In addition, the STATCOM is responsible for providing the harmonic contents required by the load, with the power grid being responsible for providing only the active power at the fundamental frequency component $(50 \mathrm{~Hz})$. However, because of the voltage supported by the power converter semiconductors (some $\mathrm{kV}$ ), a power transformer is required to interface between the STATCOM and the three-phase power grid, increasing the installation cost [7], [12], [16]. One solution would be the STATCOM based on modular and multilevel converters in order to provide the necessary voltage. In [19] some opportunities and challenges of power electronics systems in future railway electrification are presented. An example of one STATCOM composed by several IGBT devices in series is presented in [26]. A transformerless medium-voltage 
STATCOM topology based on extended MMC is presented in [27].

For simulation purposes, a DC-AC converter with the control theory presented in [24] was implemented. The simulation results are shown in Figure 7 for a railway power system powered by a V/V power transformer, and Figure 8 shows the simulation results of the system powered by a Scott power transformer.

Simulation Results of the Railway System with a STATCOM and Powered by V/V Power Transformer

This topic analyses the performance of the STATCOM to compensate for power quality problems when the railway system is powered by $\mathrm{V} / \mathrm{V}$ or Scott power transformers, and with different load values over time, as shown in Figure 7 (a) and Figure 8 (a), respectively. In this context, it is important to highlight the following figures:

- Figure 7 (b) and Figure 8 (b) represents the three-phase power grid voltages, $v_{S_{-} A}, v_{S_{-} B}$, and $v_{S_{-} C}$;

- $\quad$ Figure 7 (c) and Figure 8 (c) represents the three-phase power grid currents $i_{S_{-} A}, i_{S_{-} B}$, and $i_{S_{-} C}$;

- Figure 7 (d) and Figure 8 (d) represents the currents of the power transformer primary windings $i_{\text {Rail }} A$, $i_{\text {Rail_B }}$, and $i_{\text {Rail_C; }}$;

- $\quad$ Figure 7 (e) and Figure 8 (e) represents the compensation currents, $i_{\text {Comp_A }}, i_{C_{\text {Comp }} B}$, and $i_{\text {Comp_C }}$, synthesized by the STATCOM;

- $\quad$ Figure 7 (f) and Figure 8 (f) represents the catenaries $x$ and $y$ voltages at the secondary windings of the power transformer, $v_{x}$, and $v_{y}$;

Figure $7(\mathrm{~g})$ and Figure $8(\mathrm{~g})$ represent the currents of catenaries $x$ and $y, i_{x}$ and $i_{y}$.

At the moment that STATCOM was activated, at the time instant of $\mathrm{t}=0.04 \mathrm{~s}$, it was able to produce the harmonic contents and reactive power, required by the railway system and to compensate the NSC, making $i_{S_{-} A}$, $i_{S_{-} B}$ and $i_{S_{-} C}$ sinusoidal and balanced. In fact, the railway system continues to consume a highly distorted current, $i_{\text {Rail_A }}, i_{\text {Rail_B }}$, and $i_{\text {Rail_C}}$, as can be seen in Figure 7 (d). To highlight that, the STATCOM was able to dynamically overcome the power quality deterioration, independently of the load variations. At this moment, it is important to highlight that the compensation currents synthesized by the STATCOM had an average peak value of $20.6 \mathrm{~A}$, when the load section was equally loaded, reaching almost a twice of this when two locomotives are connected to the catenary $y$. By performing a detailed analysis of the obtained results and within the aim of calculating the harmonic distortion, it was possible to verify that the implemented system can reduce the THD ratio of the currents $i_{S_{-} A}, i_{S_{B} B}$, and $i_{S_{-} C}$, from the values presented in Table 4 , for $1.9 \%, 2.62 \%$, and $2.87 \%$ respectively. This represents an average reduction of $76.4 \%$ in terms of the THD. Analyzing, in turn, the THD of the currents on the side of the catenary, it appears that the STATCOM has no compensation capacity, maintaining the same THD value shown in Table 3 . This fact causes currents with harmonic contents to circulate through the low frequency $\mathrm{V} / \mathrm{V}$ power transformer.

Regarding the NSC/PSC ratio, the STATCOM succeeded to reduce this ratio from $100 \%$ to $0.14 \%$, when there was only one locomotive on the catenary $x$ side (from $0.04 \mathrm{~s}$ to $0.06 \mathrm{~s}$ ), and from $100 \%$ to $0.18 \%$ when there was only one locomotive on the catenary $y$ side (from $0.06 \mathrm{~s}$ to

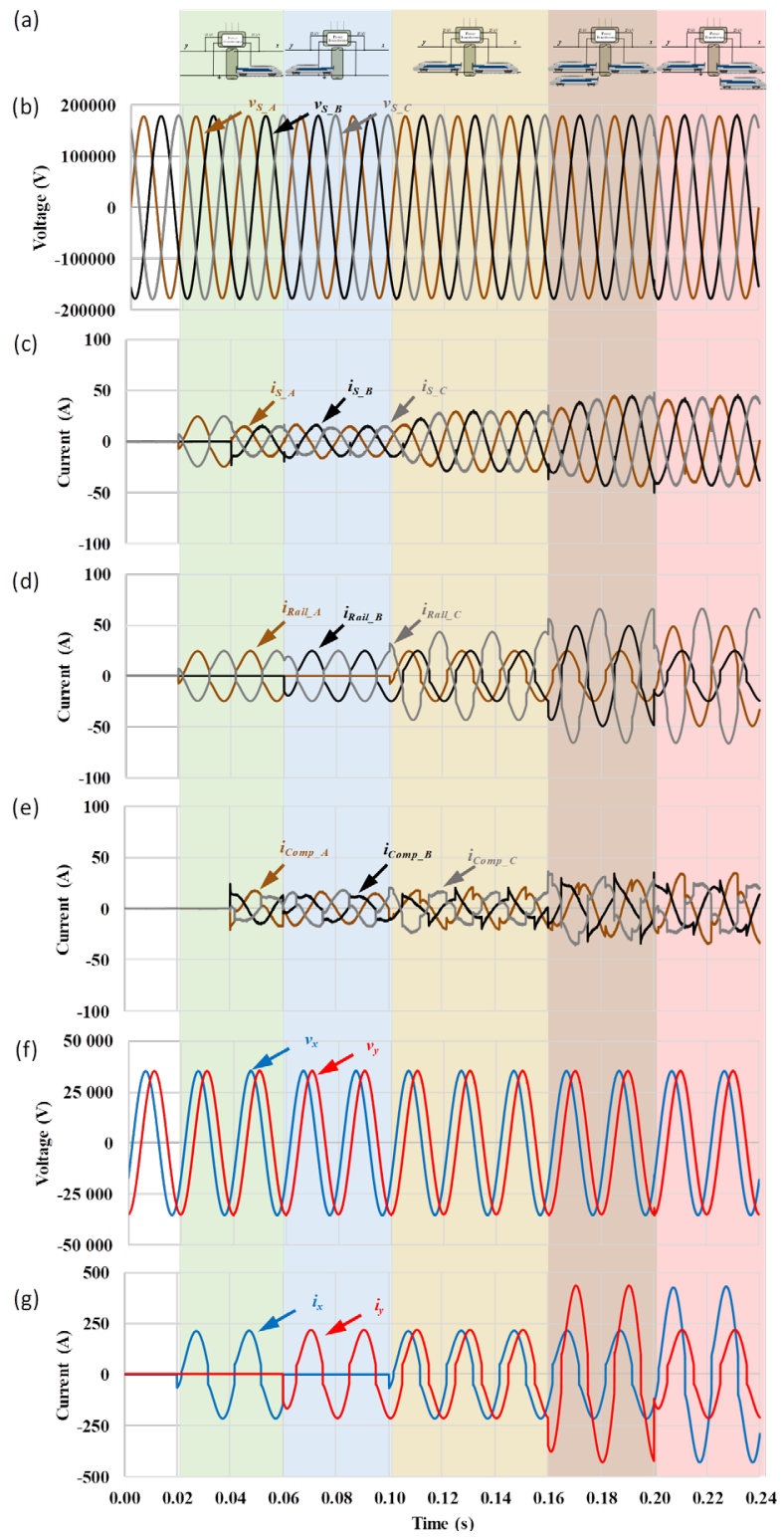

Figure 7. Simulation results of the STATCOM compensating the power quality problems existing in the railway system powered by a V/V power transformer: (a) Case scenarios with different number of locomotives in the catenaries; (b) Threephase power grid voltages $v s_{-} A, v s_{-} B$ and $v s_{-} c$; (c) Currents of the power grid is_A, is_B, is_c; (d) currents of the railway system measured at the power grid side, iRail_A, iRail_B, $i_{\text {Rail_c}} c$; (e) Compensation currents, iComp_A, icomp_B, iComp_c; (f) Voltage in the catenaries, $v_{x}$ and $v_{y} ;(\mathrm{g})$ Currents of catenaries, $i_{x}$ and $i_{y}$. 
$0.1 \mathrm{~s})$. At the interval when one locomotive was on each side (from $0.1 \mathrm{~s}$ to $0.16 \mathrm{~s}$ ), the STATCOM was able to reduce the NSC/PSC ratio from $49.9 \%$ to $0.14 \%$. Finally, when two locomotives were found on the catenary $y$ side and only one on the catenary $x$ side (from $0.16 \mathrm{~s}$ to $0.2 \mathrm{~s}$ ), the STATCOM accomplished to minimize the NSC/PSC ratio from $56.28 \%$ to $0.31 \%$. On the other hand, when two locomotives were found on the catenary $x$ side and only one on the catenary $y$ side, the STATCOM succeeded to minimize the NSC/PSC ratio of $58.38 \%$ to a value of $0.36 \%$ (from $0.2 \mathrm{~s}$ to $0.24 \mathrm{~s}$ ).

\section{Simulation Results of the Railway System with a STATCOM and Powered by Scott Power Transformer}

At the moment that the STATCOM was activated, at the time instant of $\mathrm{t}=0.04 \mathrm{~s}$, it was able to inject the harmonic contents and reactive power, required by the railway system, making $i_{S_{-} A}, i_{S_{-} B}$ and $i_{S_{-} C}$ sinusoidal and balanced. In fact, the railway system continues to consume a highly distorted current, $i_{\text {Rail } A}, i_{\text {Rail B } B}$, and $i_{\text {Rail } C}$, as can be seen in Figure 8 (d). To highlight that, the STATCOM was able to dynamically overcome the power quality deterioration, independently of the load variations. At this moment, the biggest difference between this system and the system powered by the $\mathrm{V} / \mathrm{V}$ is when the railway system had a locomotive in each catenary. As an example, at the time interval between $\mathrm{t}=0.1 \mathrm{~s}$ and $\mathrm{t}=0.16 \mathrm{~s}$, where the STATCOM only had to synthesize a compensation current with $10 \mathrm{~A}$ of peak, which represents $1 / 2$ of the value when the same system was to operate with the V/V power transformer. In general, it can be seen that the STATCOM needs to synthesize a much smaller compensation current when the railway system is powered by a Scott power transformer. To be more specific, and when the load section was equally loaded, the STATCOM had an average peak value of 11.2 A when used with the Scott power transformer. Continuing with the analysis of the obtained result, it was verified that this system was able to reduce the THD ratio of the power grid currents, $i_{S_{-} A}, i_{S_{-} B}$, and $i_{S_{-} C}$, from the values exposed in Table 4 , to $2.13 \%, 2.7 \%$, $2.68 \%$ respectively. This represents an average reduction of $78.7 \%$ in terms of the THD. Analyzing in turn the THD of the currents on the side of the catenary, it appears that the STATCOM has no compensation capacity, maintaining the same THD value shown in Table 3. This fact causes currents with harmonic content to circulate through the low frequency Scott power transformer.

Regarding the NSC/PSC ratio, the STATCOM accomplished to reduce the ratio from $100 \%$ to $0.1 \%$, when there was only one locomotive on the catenary $x$ side (from $0.04 \mathrm{~s}$ to $0.06 \mathrm{~s}$ ), and from $100 \%$ to $0.8 \%$ when there was only one locomotive on the catenary $y$ side (from $0.06 \mathrm{~s}$ to $0.1 \mathrm{~s}$ ). When a locomotive was on each side(from $0.1 \mathrm{~s}$ to $0.16 \mathrm{~s}$ ), although before the compensation the Scott transformer already provided a low NSC/PSC ratio of $0.02 \%$, the STATCOM managed to keep a low value of $0.14 \%$. Finally, when two locomotives were found on the catenary $y$ side and only one on the catenary $x$ side (from
$0.16 \mathrm{~s}$ to $0.2 \mathrm{~s}$ ), the STATCOM succeeded to minimize the NSC/PSC ratio from $32.64 \%$ to $0.23 \%$. On the other hand, when two locomotives were found on the catenary $x$ side and only one on the catenary $y$ side (from $0.2 \mathrm{~s}$ to $0.24 \mathrm{~s}$ ), the STATCOM accomplished to minimize the NSC/PSC ratio of $32.64 \%$ to a value of $0.26 \%$.

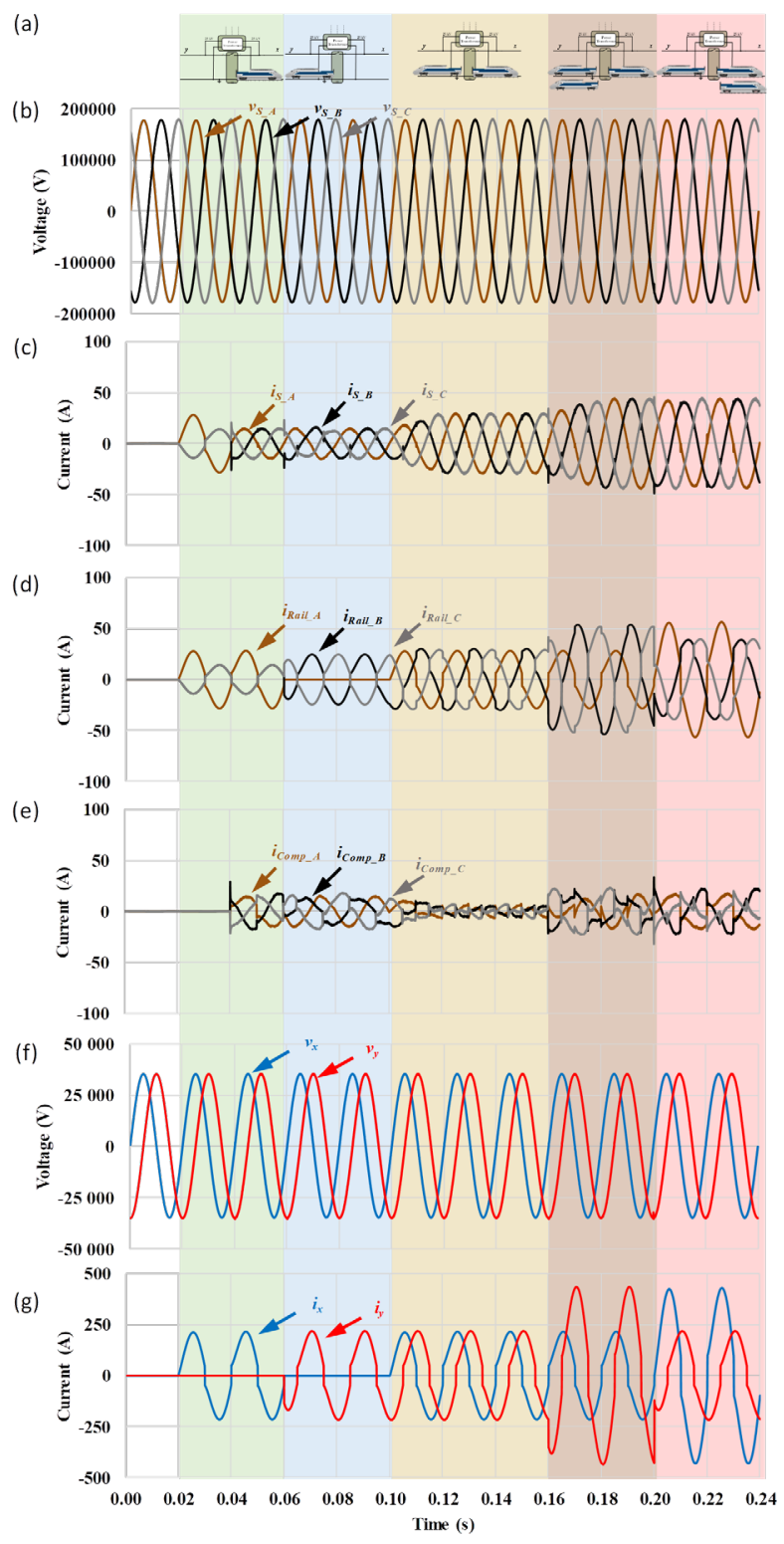

Figure 8. Simulation results of the STATCOM compensating the power quality problems existing in the railway system powered by a Scott power

transformer: (a) Case scenarios with different number of locomotives in the catenaries; (b) Threephase power grid voltages $v_{S_{-} A}, v_{S_{-} B}$ and $v_{S_{-}} ;$; (c) Currents of the power grid $i_{S_{-} A}, i_{S_{-} B}, \bar{i}_{S_{-}}$; (d) currents of the railway system measured at the power grid side, $i_{\text {Rail_A}}, i_{\text {Rail_B}}, i_{\text {Rail_C}} ;$ (e) Compensation currents, $i_{\text {Comp_A }}, i_{\text {Comp } B}, i_{\text {Comp_c }} ;$; (f) Voltage in the catenaries, $v_{x}$ and $v_{y} ;(\mathrm{g})$ Currents of catenaries, $i_{x}$ and $i_{y}$. 


\subsection{Simulation Results of the Railway System with an RPC and Power Transformers}

RPC present themselves as the most effective topology to mitigate power quality problems. This solution consists of two back-to-back power converters connected through a common DC-bus, as can be seen in Figure 9 [7], [16] [12], [21].

The fact that the RPC is connected and performs harmonic compensation on the secondary side of the power transformer, imposes that there is only the fundamental component of current circulating in the transformer, and thus, it allows to increase the efficiency of the system [8]. Additionally, since the voltage level is substantially lower on the catenary side, this topology may not require power transformers to step down the voltage level. However, depending on the topology of power electronics converters adopted, such as CC-CA back-to-back full-bridge power converter, isolation transformers are necessary in order to avoid short circuits between catenaries during the operation of the power converters. Despite this, and due to the limitations in the blocking voltages of the power semiconductors, modular and multilevel solutions similar to those presented in [18], [19], [28] are required for the correct operation. However, since the voltage and phase values in each catenary are imposed by the three-phase power transformer, there is still a need for neutral sections between the catenaries. A reduced prototype of an MMC based on half-bridge submodule topology can be found in [29]. In [30] is presented protection hardware for a halfbridge submodule that composes an MMC. Other examples of RPC used for railway applications is presented in [31], [32] and [5].

For simulation purposes, a DC-AC converter with the control theory presented in [5] was implemented. The simulation results are shown in Figure 10 for a railway power system powered by a V/V power transformer, and Figure 11 shows the simulation results of the system powered by a Scott power transformer.

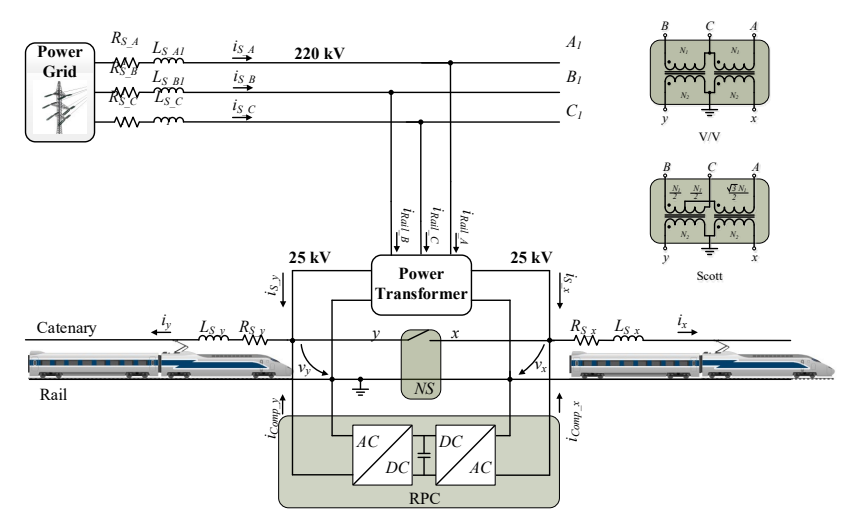

Figure 9. Electrical schematic of the RPC connection with the railway power system powered by V/V or Scott transformers.
For the following explanation, it is necessary to refer that were considered different load scenarios, as presented in Figure 10 (a) and Figure 11 (a). At the time instant $0.02 \mathrm{~s}$ an electric locomotive is added in the catenary $x$, and after the time instant $0.04 \mathrm{~s}$ the locomotive was moved to the catenary $y$. At the time instant $0.1 \mathrm{~s}$ another locomotive was added to the catenary $x$, thus leaving a locomotive in each catenary. At the time instant of $0.16 \mathrm{~s}$ there were two locomotives in the catenary $y$ and only one in the catenary $x$, reflecting an unbalanced load scenario. Finally, a similar unbalance load scenario is represented at the time instant $0.2 \mathrm{~s}$, where there were two electric locomotives in the catenary $x$ and only one in the catenary $y$. These load ratings over time were reflected in catenary currents $i_{x}$ and $i_{y}$, in catenary $x$ and catenary $y$, respectively. In this context:

- Figure 10 (b) and Figure 11 (b) represents the three-phase power grid voltages, $v_{S A}, v_{S B}$, and $v_{S C}$;

- Figure 10 (c) and Figure 11 (c) represents the three-phase power grid currents $i_{S_{-} A}, i_{S_{-} B}$, and $i_{S_{-} C}$;

Figure $10(\mathrm{~d})$ and Figure $11(\mathrm{~d})$ represents the currents of the power transformer primary windings $i_{\text {Rail }} A$, $i_{\text {Rail B }}$, and $i_{\text {Rail } C}$;

- Figure $10(\mathrm{e})$ and Figure 11 (e) represents the compensation currents, $i_{\text {Comp_A }}, i_{\text {Comp_B }}$, and $i_{\text {Comp_C }}$, synthesized by the STATCOM;

- Figure 10 (f) and Figure 11 (f) represents the catenaries $x$ and $y$ voltages at the secondary windings of the power transformer, $v_{x}$, and $v_{y}$;

- Figure $10(\mathrm{~g})$ and Figure $11(\mathrm{~g})$ represent the currents of catenaries $x$ and $y, i_{x}$ and $i_{y}$.

\section{Simulation Results of the Railway System with a} RPC and Powered by V/V Power Transformer

At the moment that RPC is activated, at the time instant of $\mathrm{t}=0.04 \mathrm{~s}$, it was able to produce the harmonic contents and reactive power, required by the railway system and compensating the NSC, making $i_{S_{-} A}, i_{S_{-} B}$, and $i_{S_{-} C}$ sinusoidal and balanced. In fact, the catenary of the railway system continues to consume a highly distorted current, $i_{x}$, and $i_{y}$, as can be seen in Figure 10 (d). However, and unlike the STATCOM, the power transformer V/V only have the fundamental component of current, having sinusoidal voltages, $v_{x}$ and $v_{y}$, and sinusoidal currents, $i_{x}$ and $i_{y}$. To highlight that, the RPC was able to dynamically overcome the power quality deterioration, independently of the load variations. At this moment, it is important to highlight that the compensation currents synthesized by the RPC have an average peak value of $172.3 \mathrm{~A}$, when the load section was equally loaded, reaching almost twice of this when two locomotives was connected to the catenary $y$. By performing a detailed analysis of the obtained results and within the aim of calculating the harmonic distortion, it was possible to verify that the implemented system can reduce the THD ratio of the currents $i_{S_{-} A}, i_{S_{-} B}$, and $i_{S_{-} C}$, from the values presented in Table 4 , for $3.78 \%, 3.8 \%$ and $5.72 \%$ respectively. This represents an average reduction of $56 \%$ in terms of the THD. Analyzing, in turn, the THD of the $i_{x}$ and $i_{y}$, it appears that the RPC makes it possible to decrease the harmonic content of the currents that circulate through 
the transformer, decreasing from the THD values presented in Table 3 to $3.65 \%$ and $3.88 \%$, respectively. This represents an average reduction of $68.6 \%$ in terms of the THD.

Regarding the NSC/PSC ratio, the RPC succeeded to reduce it from $100 \%$ to $0.28 \%$, when there was only one locomotive on the catenary $x$ side (from $0.04 \mathrm{~s}$ to $0.06 \mathrm{~s}$ ), and from $100 \%$ to $0.2 \%$ when there was only one

(a)

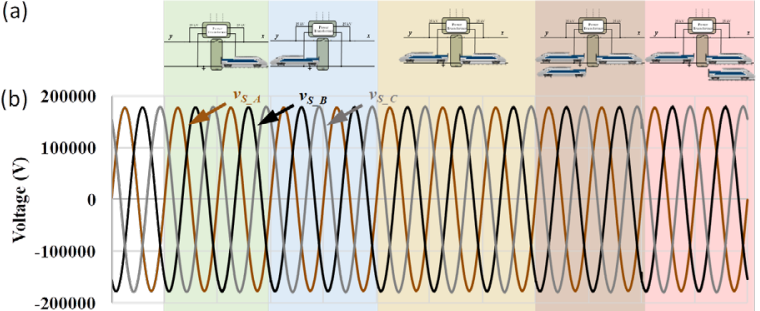

(c)
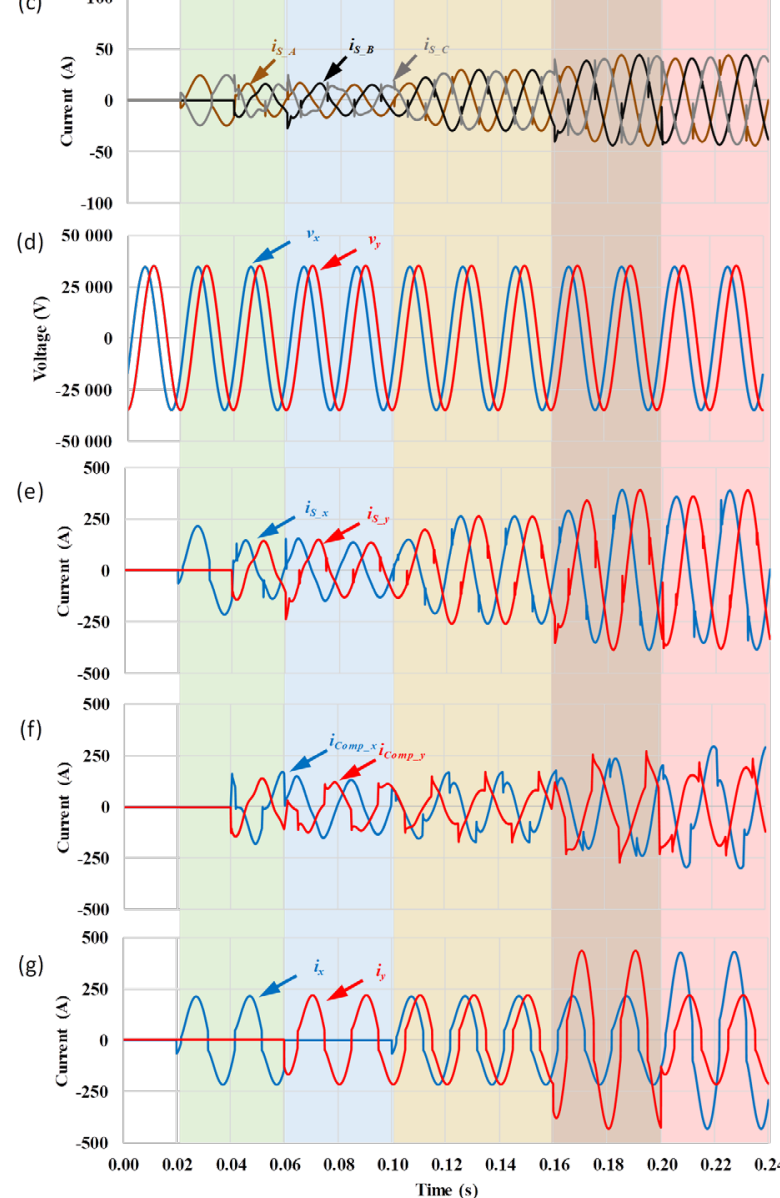

Figure 10. Simulation results of the RPC compensating the power quality problems existing in the railway system powered by a V/V power transformer: (a) Case scenarios with different number of locomotives in the catenaries; (b) Threephase power grid voltages $V s_{-} A, V s_{-} B$ and $V s_{-} c$; (c)

Currents of the power grid is_A, is_B, is_c; (d) Voltage in the catenaries, $v_{x}$ and $v_{y} ;(\mathrm{e})$ Currents in the low-voltage side of the V/V power transformer, $i_{x}$ and $i_{y} ;(\mathrm{e})$ Compensation currents, $i_{\text {Comp } x}$ and

$i_{\text {Comp_y }},(\mathrm{f})$ Currents of catenaries, $i_{x}$ and $i_{y}$. locomotive on the catenary $y$ side (from $0.06 \mathrm{~s}$ to $0.1 \mathrm{~s}$ ). When a locomotive was on each side (from $0.1 \mathrm{~s}$ to $0.16 \mathrm{~s}$ ), the RPC accomplished to reduce the NSC/PSC ratio from $49.9 \%$ to $0.36 \%$. Finally, when two locomotives were found on the catenary $y$ side and only one on the catenary $x$ side (from $0.16 \mathrm{~s}$ to $0.2 \mathrm{~s}$ ), the RPC was able to minimize the NSC/PSC ratio from $56.28 \%$ to $0.38 \%$. On the other hand, when two locomotives were found on the catenary $x$ side and only one on the catenary $y$ side (from $0.2 \mathrm{~s}$ to $0.24 \mathrm{~s}$ ), the RPC accomplished to minimize the NSC/PSC ratio of $58.38 \%$ to a value of $0.4 \%$.

\section{Simulation Results of the Railway System with an RPC Powered by Scott Power Transformer}

At the moment that the RPC was activated, at the time instant of $\mathrm{t}=0.04 \mathrm{~s}$, it was able to produce the harmonic contents and reactive power, required by the railway system and compensating the NSC, making $i_{S A}, i_{S} B$ and $i_{S C}$ sinusoidal and balanced. In fact, the catenary of the railway system continues to consume a highly distorted current, $i_{x}$, and $\mathrm{i}_{y}$, as can be seen in Figure $11(\mathrm{~d})$. However, and unlike with the STATCOM, the Scott power transformer with the RPC only have the fundamental component of current, having sinusoidal voltages, $v_{x}$ and $v_{y}$, and sinusoidal currents, $i_{x}$ and $i_{y}$. To highlight that, the RPC was able to dynamically overcome the power quality deterioration, independently of the load variations. At this moment, the biggest difference between this system and the system powered by the $\mathrm{V} / \mathrm{V}$ is when the railway system has a locomotive in each catenary. As an example, at the time instant between $\mathrm{t}=0.1 \mathrm{~s}$ and $\mathrm{t}=0.16 \mathrm{~s}$, where $\mathrm{RPC}$ only has to synthesize a compensation current with $10 \mathrm{~A}$ of peak, which represents $1 / 2$ of the value when the same system was to operate with the $\mathrm{V} / \mathrm{V}$ power transformer. In general, it can be seen that the RPC needs to synthesize a much smaller compensation current when the railway system is powered by a Scott power transformer. To be more specific, and when the catenary sections was equally loaded, the RPC have an average peak value of $54.4 \mathrm{~A}$ when is used with the Scott power transformer. Continuing with the analysis of the obtained result, it was verified that this system was able to reduce the THD ratio of the power grid currents, $i_{S_{-} A}, i_{S_{-} B}$, and $i_{S_{-} C}$, from the values exposed in Table 4 , to $3.89 \%, 3.77 \%, 3.9 \%$ respectively. This represents an average reduction of $67 \%$ in terms of the THD. Analyzing, in turn, the THD of the $i_{x}$ and $i_{y}$, it appears that the RPC makes it possible to decrease the harmonic content of the currents that circulate through the transformer, decreasing from the THD values presented in Table 3 to $3.77 \%$ and $3.86 \%$, respectively. This represents an average reduction of $67.7 \%$ in terms of the THD.

Regarding the NSC/PSC ratio, the RPC succeeded to reduce it from $100 \%$ to $0.33 \%$, when there was only one locomotive on the catenary $x$ side (from $0.04 \mathrm{~s}$ to $0.06 \mathrm{~s}$ ), and from $100 \%$ to $0.17 \%$ when there was only one locomotive on the catenary $y$ side (from $0.06 \mathrm{~s}$ to $0.1 \mathrm{~s}$ ). When a locomotive was on each side (from $0.1 \mathrm{~s}$ to $0.16 \mathrm{~s}$ ), although before the compensation the Scott transformer already provided a low NSC/PSC ratio of $0.02 \%$, the RPC 
was able to keep a low value of $0.21 \%$. Finally, when two locomotives were found on the catenary $y$ side and only one on the catenary $x$ side (from $0.16 \mathrm{~s}$ to $0.2 \mathrm{~s}$ ), the RPC managed to minimize the NSC/PSC ratio from $32.64 \%$ to $0.18 \%$. On the other hand, when two locomotives were found on the catenary $x$ side and only one on the catenary $y$ side (from $0.2 \mathrm{~s}$ to $0.24 \mathrm{~s}$ ), the RPC accomplished to

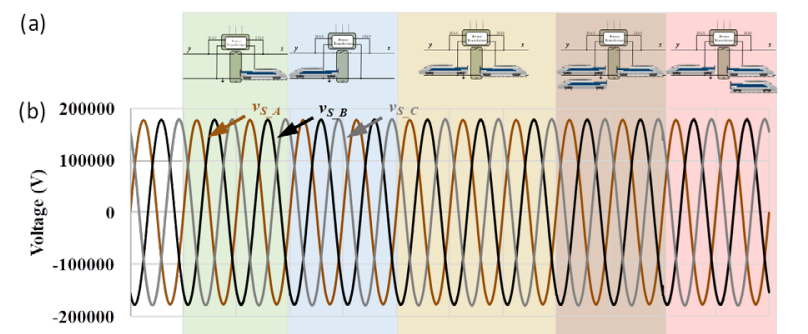

$$
\text { (c) }
$$$$
-200000
$$
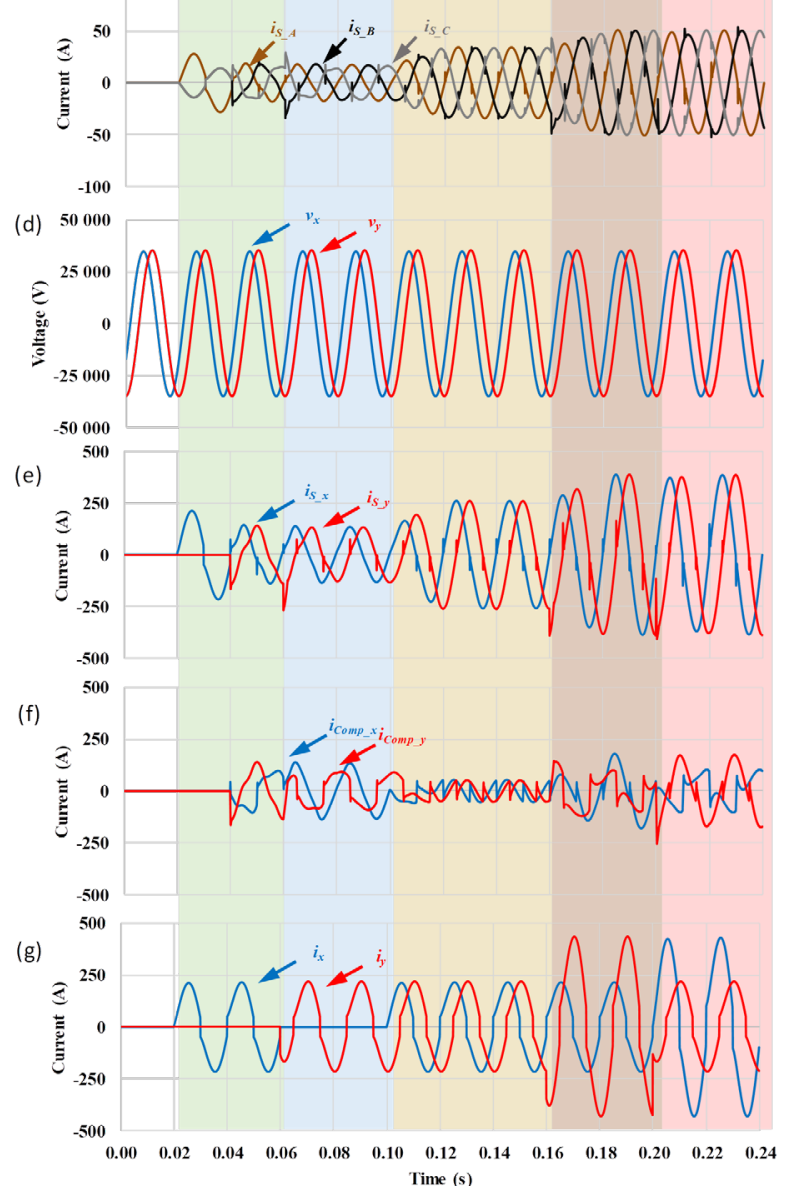

Figure 11. Simulation results of the RPC compensating the power quality problems existing in the railway system powered by a Scott power

transformer: (a) Case scenarios with different number of locomotives in the catenaries; (b) Threephase power grid voltages $V s_{-} A, V s_{-} B$ and $v s_{-} c$; (c)

Currents of the power grid is_A, is_B, is_c; (d) Voltage in the catenaries, $v_{x}$ and $v_{y} ;(\mathrm{e})$ Currents in the low-voltage side of the V/V power transformer, $i_{x}$ and $i_{y} ;(\mathrm{e})$ Compensation currents, $i_{\text {Comp_x }}$ and

$i_{\text {Comp_y }},(\mathrm{f})$ Currents of catenaries, $i_{x}$ and $i_{y}$. minimize the NSC/PSC ratio of $32.64 \%$ to a value of $0.25 \%$.

\subsection{Evaluation Performance of the $V / V$ and Scott Power Transformers}

In order to evaluate the performance of the STATCOM and of the RPC with different power transformers, the harmonic contents in the three-phase power grid were analysed. For that purpose, it was only considered the scenario when both of the catenary load. That is, section $x$ and $y$ were equally loaded with one locomotive for each section, as represented in the interval between $t=0.10 \mathrm{~s}$ and $\mathrm{t}=0.16 \mathrm{~s}$.

Initially and by considering a railway system powered by a V/V power transformer and without any dynamic compensation, the harmonic spectrum of the $i_{S_{-} A}, i_{S_{-} B}$ and $i_{S_{-} C}$ is shown in Figure 12 (a). At that case, the harmonic content in $i_{S_{-} A}$ is similar to the ones of $i_{S_{-} B}$, being $i_{S_{-} C}$ with a higher amplitude. On the contrary, $i_{S_{-} C}$ has a lower value in the $3^{\text {rd }}, 9^{\text {th }}$ and $15^{\text {th }}$ harmonics. Considering now that the railway power system is powered by a Scott power transformer, it is possible to see the harmonic spectrum of the $i_{S_{-} A}, i_{S_{B} B}$, and $i_{S_{C}}$ presented in Figure 12 (b). In this case, it can be verified that the harmonic content of the fundamental component is more uniform. Since similar operating conditions was found in each overhead catenary line, the harmonic content is similar as shown in Figure 12 (c) and Figure 12 (d).

When a dynamic compensation is performed by the STATCOM, it is possible to see in Figure 12 (e) and in Figure 12 (f), for a railway system powered by V/V and Scott power transformers, respectively, that the active power conditioner was able to reduce the harmonic content in $i_{S_{-} A}, i_{S_{-} B}$, and $i_{S_{-} C}$. On the other hand, the harmonic content in $i_{x}$ and $\bar{i}_{y}$ after compensation do not show a difference, as can be seen in Figure $12(\mathrm{~g})$ and in Figure 12 (h).

On the other hand, when a dynamic compensation is performed by the RPC, it is possible to see in Figure 12 (i) and in Figure 12 (j), for a railway system powered by V/V and Scott power transformers, respectively, that the active power conditioner was able to reduce the harmonic content in $i_{S_{-} A}, i_{S_{-} B}$ and $i_{S_{-} C}$. Additionally, the RPC is also capable to reduce the harmonic content in $i_{x}$ and $i_{y}$, as can be seen in Figure 12 (k) and in Figure 12 (1).

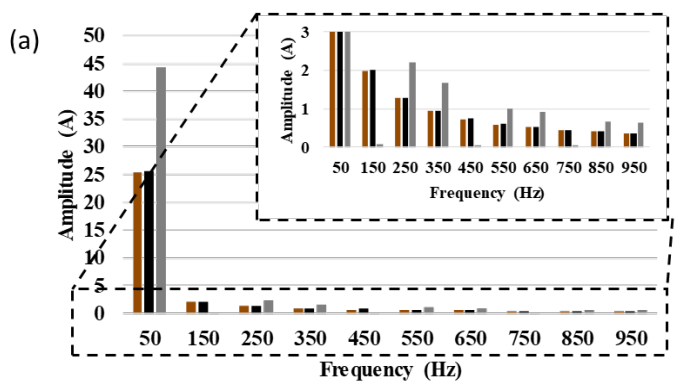


(b)

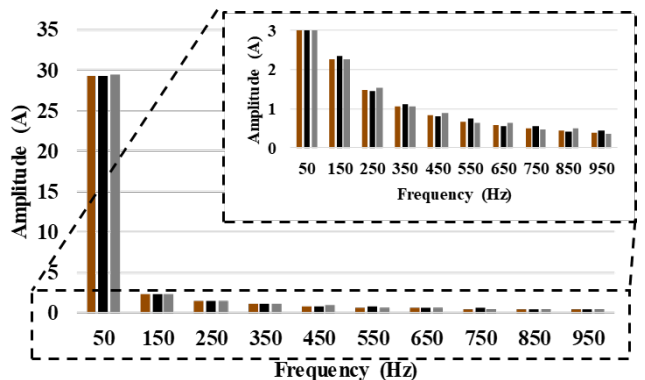

(c)

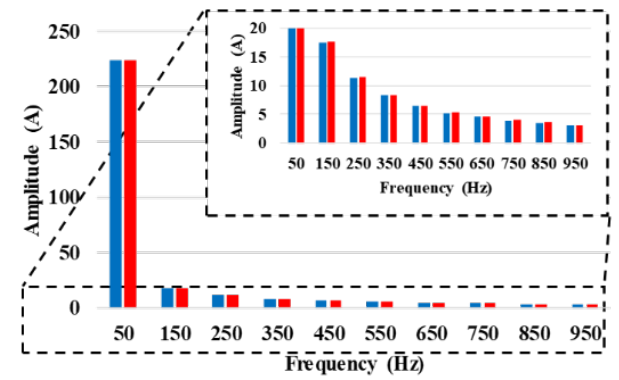

(d) $\quad 250$

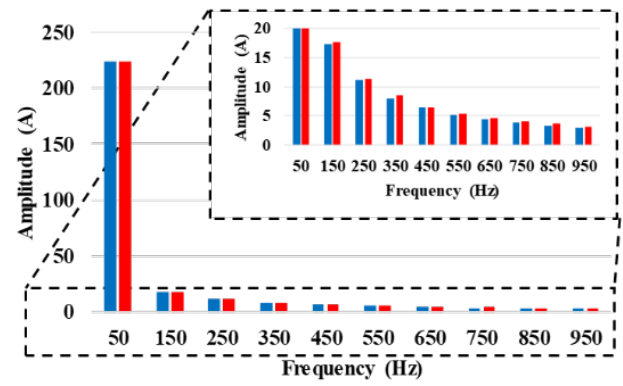

(e) 35

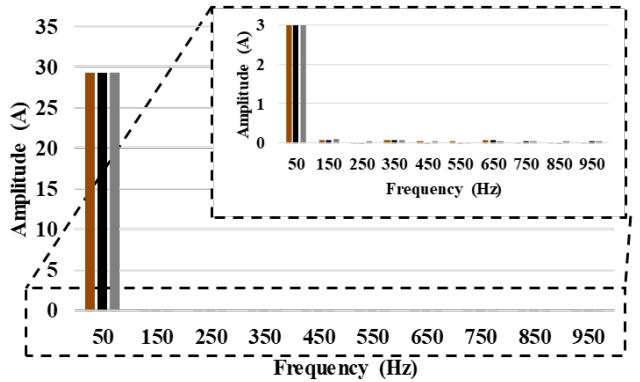

(f)

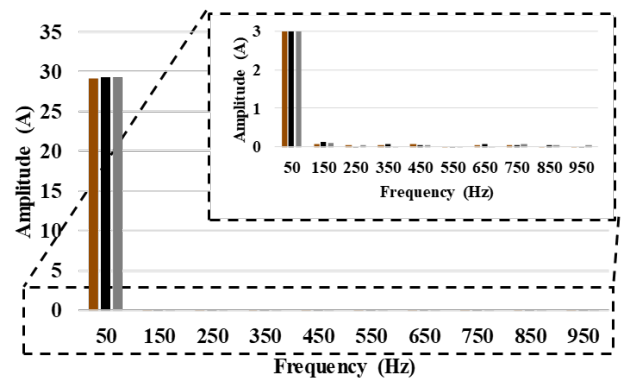

(g) $\quad 250$

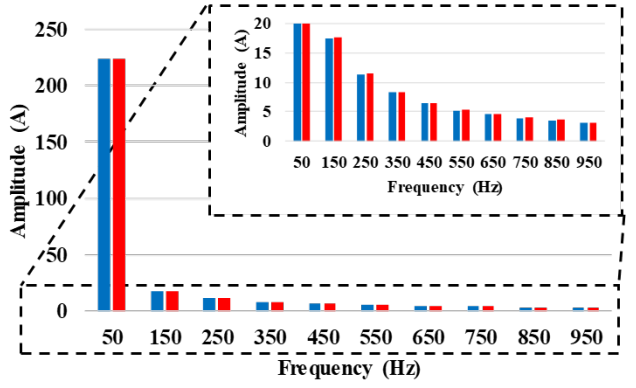

(h)

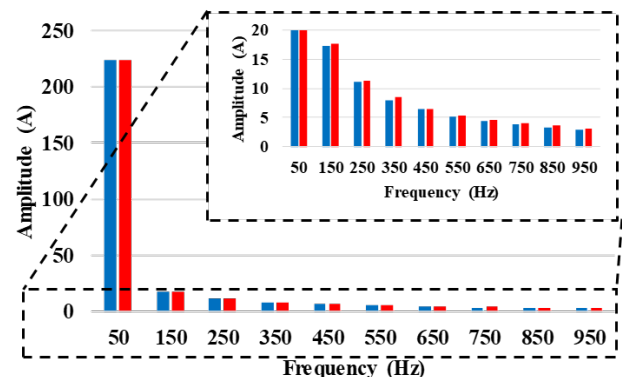

(i)

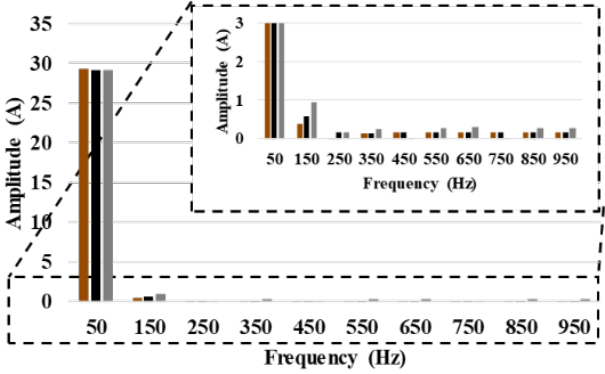

(j)

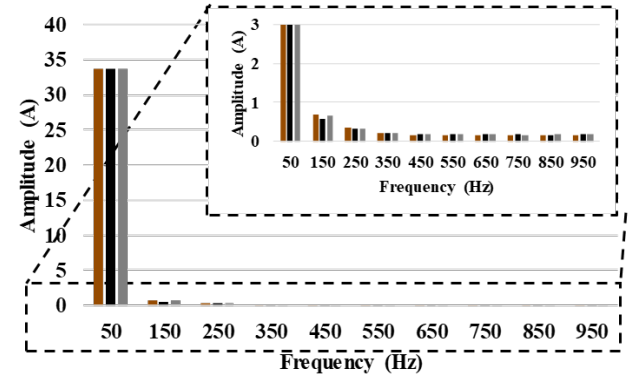

(k) $\quad 300$

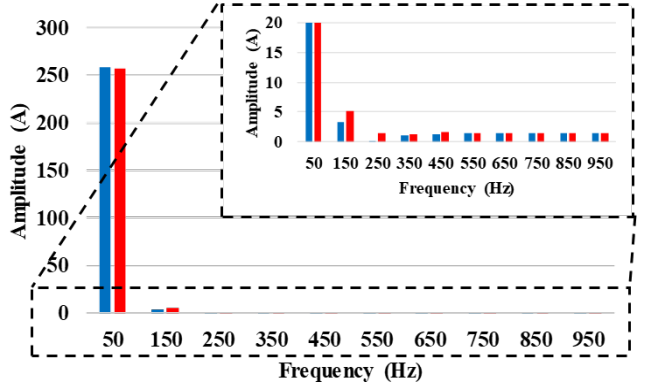

(l)

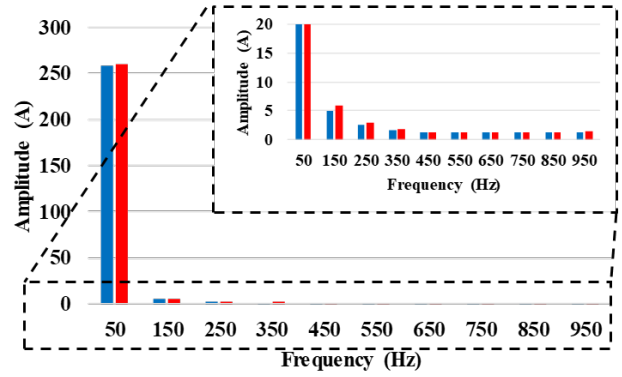

Figure 12. Harmonic spectrum of the currents in the three-phase power grid and in the catenary, before and after STATCOM or RPC compensation

Regarding the compensation currents during the interval when one locomotive is found in each catenary, it is possible to verify that when a $\mathrm{V} / \mathrm{V}$ power transformer is 
used, the RPC compensation current is 8.75 times higher, on average, than the compensation current synthesized by the STATCOM. In turn, when the Scott power transformer is used, this difference rises to 11.8 times. That said, and taking into account a modular and multilevel implementation with similar topologies and voltages on the DC-bus, the use of a greater number of sub-modules in the STATCOM is expected, not only because it is a threephase system but also because of its operating voltages. On the other hand, and since the catenary voltages was substantially lower than the voltages in the electrical distribution network and it is a single-phase system, the need for submodules is lower. However, the powers of each sub-module of the RPC will have to be higher in relation to the sub-modules that make up the STATCOM due to the values of the compensation currents.

\section{Conclusions}

This paper presents the importance of a Static Synchronous Compensator (STATCOM) and the Rail Power Conditioner (RPC) in the electrified railway systems when using V/V or Scott power transformer. Simulation results of the STATCOM and the RPC for dynamic compensation are presented. For this study, it was considered a different number of locomotives (different loading conditions) along the overhead catenary lines.

Simulation results show that Scott power transformer is able to present a system more balanced when electric locomotives are equally distributed over the catenary lines. However, the Scott power transformer has an asymmetric operating mode when one of the overhead catenary lines has more loads than the other. In turn, despite the fact that the $\mathrm{V} / \mathrm{V}$ transformer cannot balance the railway system like the Scott transformer, it has a more symmetrical mode of operation regardless of the catenary with more locomotives. Results show that V/V power transformer has less capability to overcome unbalance and harmonic distortions in the three-phase power grid. However, it has more simple structure and lower costs than the Scott power transformer.

The compensation currents are lower when the active power conditioners are complemented with the Scott transformer. This fact is more evident when the catenaries are equally loaded.

Regarding the relationship between the Negative Sequence Components (NSC) and the Positive Sequence Components (PSC), it was found that this relationship is usually less with the Scott than with the V/V power transformers. When one side of the catenary has no locomotives, in both cases the NSC/PSC ratio reaches $100 \%$. In turn, when similar locomotives are found on each side of the overhead contact line, the system powered by the Scott power transformer has an NSC/PSC ratio of $0.02 \%$. In contrast, when fed with a $\mathrm{V} / \mathrm{V}$ power transformer, the NSC/PSC ratio rises to values close to $49.9 \%$. When one of the catenary sides has twice as many locomotives and is powered by a Scott power transformer, the NSC/PSC ratio has a value of $32.64 \%$. In contrast, with $\mathrm{V} / \mathrm{V}$ transformers, the NSC/PSC ratio almost doubles, presenting a value of $56.28 \%$ when the catenary $y$ side presents twice as many locomotives, and a value of $58.28 \%$ when the catenary $x$ side presents the double as locomotives. When the compensation system was activated, in any of the load scenarios of the V/V or Scott power transformer, and with the STATCOM or with the RPC compensation topologies, it was possible to obtain an NSC/PSC ratio always lower than $1 \%$. Additionally, and considering the railway system fed by Scott power transformers, it was always possible to obtain a better NSC/PSC ratio when section y had more locomotives than section $x$.

From an implementation point of view, the RPC solution has a simpler structure, since it is connected on the single-phase side and with lower voltage. Considering the modular and multilevel solutions, with similar topologies and voltages on the DC-bus, the RPC would need a lower number of sub-modules, required, on the other hand, that each sub-module should be sized for a higher power.

Nevertheless, and once that the RPC mitigates the problems of power quality closest to its origin, it allows that only the fundamental component components of current circulates through the low frequency power transformers, which allows to improve the efficiency of the system as well as to preserve the lifetime of the rail system components.

With this study, it was possible to conclude that the V/V and Scott power transformers complemented with the RPC present themselves as a very interesting solution for the mitigation of power quality problems in the railway systems. For future work, it would be interesting to analyse the economic feasibility of implementing a system with $\mathrm{V} / \mathrm{V}$ or Scott, taking into account the principle of operation mentioned throughout the paper of each solution. Nevertheless, an analysis at the power level of each submodule that makes up the modular multilevel converter would be equally interesting from the point of view of practical implementation.

\section{Acknowledgements.}

This work has been supported by FCT - Fundação para a Ciência e Tecnologia with-in the Project Scope: UIDB/00319/2020. This work has been supported by the FCT Project QUALITY4POWER PTDC/EEI-EEE/28813/2017, and by the FCT Project DAIPESEV PTDC/EEI-EEE/30382/2017. Mr. Luis A. M. Barros is supported by the doctoral scholarship $\mathrm{PD} / \mathrm{BD} / 143006 / 2018$ granted by the Portuguese FCT foundation. Mr. Mohamed Tanta was supported by FCT PhD grant with a reference $\mathrm{PD} / \mathrm{BD} / 127815 / 2016$.

\section{References}

[1] M. Brenna, F. Foiadelli, and D. Zaninelli, Electrical railway transportation systems, vol. 67. John Wiley \& Sons, 2018, ISBN: 978-1-119-38680-3. 
[2] S. Frey, Railway Electrification Systems \& Engineering. White word publications, 2012, ISBN: 978-81-323-43950 .

[3] N. Mazzino, X. Perez, N. Furio, and others, "Rail 2050 Vision: Rail-the Backbone of Europe's Mobility," ERRAC-The European Rail Research Advisory Council, Technical Report, 2017.

[4] R. Targosz and D. Chapman, "Application note-cost of poor power quality," Leonardo Energy, 2012.

[5] A. Luo, C. Wu, J. Shen, Z. Shuai, and F. Ma, "Railway static power conditioners for high-speed train traction power supply systems using three-phase V/V transformers," IEEE Transactions on Power Electronics, vol. 26, no. 10, pp. 2844-2856, 2011, doi: 10.1109/TPEL.2011.2128888.

[6] I. Krastev, P. Tricoli, S. Hillmansen, and M. Chen, "Future of electric railways: advanced electrification systems with static converters for ac railways," IEEE Electrification Magazine, vol. 4, no. 3, pp. 6-14, 2016, doi: 10.1109/MELE.2016.2584998

[7] M. Tanta, V. Monteiro, T. J. Sousa, A. P. Martins, A. S. Carvalho, and J. L. Afonso, "Power quality phenomena in electrified railways: Conventional and new trends in power quality improvement toward public power systems," in Young Engineers Forum (YEF-ECE), 2018 International, 2018, pp. 25-30, doi: 10.1109/YEFECE.2018.8368934

[8] K.-W. Lao, M.-C. Wong, and N. Dai, Co-phase Traction Power Supply with Railway Hybrid Power Ouality Conditioner. Springer, 2019, doi: 10.1007/978-981-130438-5, ISBN: 978-981-13-0438-5.

[9] K.-W. Lao, M.-C. Wong, N. Dai, C.-S. Lam, L. Wang, and C.-K. Wong, "Analysis of the Effects of Operation Voltage Range in Flexible DC Control on Railway HPQC Compensation Capability in High-Speed Co-phase Railway Power," IEEE Transactions on Power Electronics, vol. 33, no. 2, pp. 1760-1774, 2018, doi: 10.1109/TPEL.2017.2684427.

[10] A. Steimel, Electric Traction - Motive Power and Energy Supply: Basics and Practical Experience. Oldenbourg Industrieverlag, 2008, ISBN: 978-3-8356-3132-8.

[11] L. A. Barros, M. Tanta, A. P. Martins, J. L. Afonso, and J. Pinto, "STATCOM Evaluation in Electrified Railway Using V/V and Scott Power Transformers," in International Conference on Sustainable Energy for Smart Cities, 2019, pp. 18-32, doi: 10.1007/978-3-030-4569482.

[12] S. M. M. Gazafrudi, A. T. Langerudy, E. F. Fuchs, and K. Al-Haddad, "Power quality issues in railway electrification: A comprehensive perspective," IEEE transactions on industrial electronics, vol. 62, no. 5, pp. 3081-3090, 2015, doi: 10.1109/TIE.2014.2386794.

[13] A. P. Martins, V. A. Morais, and C. J. Ramos, "Analysis of the STATCOM/Balancer Robustness in Railway Applications," in 2020 IEEE 14th International Conference on Compatibility, Power Electronics and Power Engineering (CPE-POWERENG), 2020, vol. 1, pp. 69-75, doi: 10.1109/CPEPOWERENG48600.2020.9161641.

[14] P. Rodrigues, V. A. Morais, A. Martins, and A. Carvalho, "STATCOM Simulation Models for Analysis of Electrified Railways," in IECON 2019-45th Annual Conference of the IEEE Industrial Electronics Society, 2019, vol. 1, pp. 2257-2262, doi: 10.1109/IECON.2019.8927256.
[15] F. Ma, Z. He, Q. Xu, A. Luo, L. Zhou, and M. Li, "Multilevel power conditioner and its model predictive control for railway traction system," IEEE Transactions on Industrial Electronics, vol. 63, no. 11, pp. 7275-7285, 2016, doi: 10.1109/TIE.2016.2563379.

[16] F. Ma, Y. Li, and et al., "A railway traction power conditioner using modular multilevel converter and its control strategy for high-speed railway system," IEEE Transactions on Transportation Electrification, vol. 2, no. 1, pp. 96-109, 2016, doi: 10.1109/TTE.2016.2515164.

[17] M. Tanta, L. A. Barros, J. Pinto, A. P. Martins, and J. L. Afonso, "Modular multilevel converter in electrified railway systems: applications of rail static frequency converters and rail power conditioners," in 2020 International Young Engineers Forum (YEF-ECE), 2020, pp. 55-60, doi: 10.1109/YEF-ECE49388.2020.9171814.

[18] M. Tanta, J. G. Pinto, A. P. Martins, A. S. Carvalho, and J. L. Afonso, "Topologies and Operation Modes of Rail Power Conditioners in AC Traction Grids: Review and Comprehensive Comparison," Energies - MDPI, 2020.

[19] L. A. M. Barros, M. Tanta, A. P. Martins, J. L. Afonso, and J. G. Pinto, "Opportunities and Challenges of Power Electronics Systems in Future Railway Electrification," IEEE CPE - POWERENG 2020: 14th International Conference on Compatibility, Power Electronics and Power Engineering, 2020, doi: 10.1109/CPEPOWERENG48600.2020.9161695.

[20] L. Abrahamsson, T. Schütte, and S. Östlund, "Use of converters for feeding of AC railways for all frequencies," Energy for Sustainable Development, vol. 16, no. 3, pp. 368-378, 2012, doi: 10.1016/j.esd.2012.05.003.

[21] K. Lee, "Advances in the application of power electronics to railway traction," in Power Electronics Systems and Applications (PESA), 2015 6th International Conference on, 2015, pp. 1-4, doi: 10.1109/PESA.2015.7398960.

[22] D. Serrano-Jiménez, L. Abrahamsson, S. Castaño-Solis, and J. Sanz-Feito, "Electrical railway power supply systems: Current situation and future trends," International Journal of Electrical Power $1 \&$ Energy Systems, vol. 92, pp. 181-192, 2017, doi: 10.1016/j.ijepes.2017.05.008.

[23] Q. Xu, F. Ma, Z. He, Y. Chen, J. M. Guerrero, A. Luo, Y. $\mathrm{Li}$, and Y. Yue, "Analysis and comparison of modular railway power conditioner for high-speed railway traction system," IEEE Trans. Power Electron., vol. 32, no. 8, pp. 6031-6048, 2017, doi: 10.1109/TPEL.2016.2616721.

[24] J. Pinto, M. Tanta, V. D. F. Monteiro, L. A. Barros, and J. L. Afonso, "Active power conditioner based on a voltage source converter for harmonics and negative sequence components compensation in electrified railway systems," in Proceedings of 7th Transport Research Arena TRA 2018, 2018, doi: 10.5281/zenodo.1491309.

[25] Z. Xu, L. Luo, Z. Zhang, and Y. Li, "A novel asymmetrical connection balance transformer for traction power supply," Turkish Journal of Electrical Engineering and Computer Science, vol. 23, no. 5, p. 1284, 2015, doi: 10.3906/ELK-1304-195.

[26] K. Fujii, K. Kunomura, K. Yoshida, A. Suzuki, S. Konishi, M. Daiguji, and K. Baba, "STATCOM applying flatpackaged IGBTs connected in series," IEEE transactions on power electronics, vol. 20, no. 5, pp. 1125-1132, 2005, doi: 10.1109/TPEL.2005.854054.

[27] M. T. Bina and others, "A transformerless mediumvoltage STATCOM topology based on extended modular multilevel converters," IEEE Transactions on Power 
Electronics, vol. 26, no. 5, pp. 1534-1545, 2011, doi: 10.1109/TPEL.2010.2085088.

[28] M. Tanta, J. Pinto, V. Monteiro, A. P Martins, A. S Carvalho, and J. L Afonso, "Deadbeat Predictive Current Control for Circulating Currents Reduction in a Modular Multilevel Converter Based Rail Power Conditioner," Applied Sciences, vol. 10, no. 5, p. 1849, 2020, doi: 10.3390/app10051849.

[29] M. Tanta, J. Cunha, L. A. Barros, V. Monteiro, J. Pinto, A. P. Martins, and J. L. Afonso, "Experimental Validation of a Reduced-Scale Rail Power Conditioner Based on Modular Multilevel Converter for AC Railway Power Grids," Energies, vol. 14, no. 2, p. 484, 2021, doi: 10.3390/en14020484.

[30] M. Tanta, J. Cunha, V. Monteiro, A. P. Martins, A. S. Carvalho, and J. L. Afonso, "A novel hardware protection scheme for a modular multilevel converter half-bridge submodule," in IECON 2019-45th Annual Conference of the IEEE Industrial Electronics Society, 2019, vol. 1, pp. 6043-6048, doi: 10.1109/IECON.2019.8927361.

[31] A. Luo, F. Ma, C. Wu, S. Q. Ding, Q.-C. Zhong, and Z. K. Shuai, "A dual-loop control strategy of railway static power regulator under V/V electric traction system," IEEE Transactions on Power Electronics, vol. 26, no. 7, pp. 2079-2091, 2011, doi: 10.1109/TPEL.2010.2103383.

[32] M. Ohmi and Y. Yoshii, "Validation of railway static power conditioner in Tohoku Shinkansen on actual operation," in The 2010 International Power Electronics Conference-ECCE ASIA-, 2010, pp. 2160-2164, doi: 10.1109/IPEC.2010.5544563. 